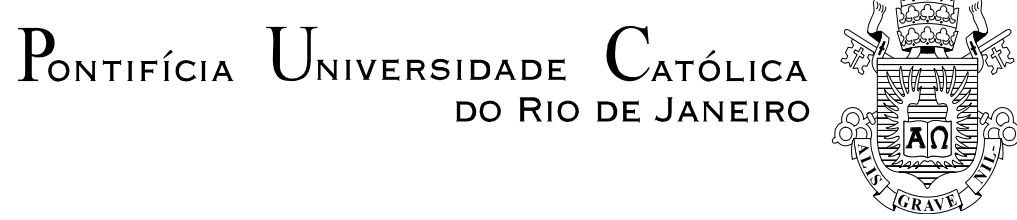

Ricardo José Lodi Ferreira

Consumidores de baixa renda e o seu

"Eu" estendido em veículos

Dissertação de Mestrado

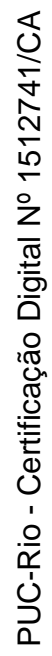

Dissertação apresentada ao Programa de Pós-graduação em Administração de Empresas da PUC-Rio como requisito parcial para obtenção do grau de Mestre em Administração de Empresas.

Orientador: Prof. Marcus Wilcox Hemais

Rio de Janeiro

Abril de 2017 


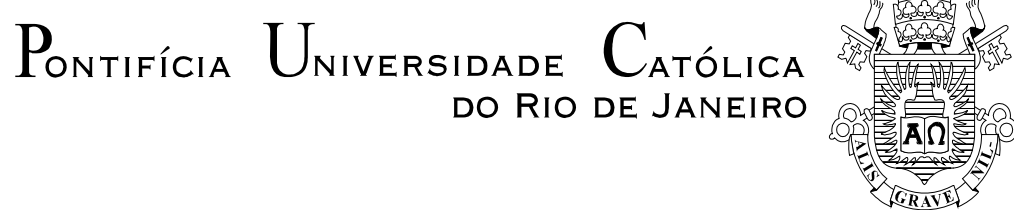

Ricardo José Lodi Ferreira

\section{Consumidores de baixa renda e o seu \\ "Eu" estendido em veículos}

Dissertação apresentada como requisito parcial para obtenção do grau de Mestre pelo Programa de PósGraduação em Administração de Empresas do Departamento de Administração da PUC-Rio. Aprovada pela Comissão Examinadora abaixo assinada.

Prof. Marcus Wilcox Hemais

Orientador

Departamento de Administração - PUC-Rio

Prof. Luis Alexandre Grubits de Paula Pessôa

Departamento de Administração - PUC-Rio

Profa. Denise Franca Barros

Universidade do Grande Rio

Profa. Mônica Herz

Vice-Decana de Pós-Graduação do CCS - PUC-Rio

Rio de Janeiro, 10 de abril de 2017 
Todos os direitos reservados. É proibida a reprodução total ou parcial do trabalho sem autorização da universidade, do autor e do orientador.

\section{Ricardo José Lodi Ferreira}

Graduou-se em Administração na UVA-RJ.

Ficha catalográfica

Ferreira, Ricardo José Lodi

Consumidores de baixa renda e o seu "Eu" estendido em veículos / Ricardo José Lodi Ferreira; orientador: Marcus Wilcox Hemais. - 2017.

$70 \mathrm{f} . ; 30 \mathrm{~cm}$

Dissertação (mestrado) - Pontifícia Universidade Católica do Rio de Janeiro, Departamento de Administração, 2017.

Inclui bibliografia

1. Administração - Teses. 2. Consumidor de baixa renda. 3. "Eu" estendido. 4. Veículo. 5. CCT. 6. Consumo. I. Hemais, Marcus Wilcox. II. Pontifícia Universidade Católica do Rio de Janeiro. Departamento de Administração. III. Título.

CDD: 658 
Aos meus pais, José e Lúcia, pois me deram, me dão e sempre me darão apoio para prosseguir nos estudos e na vida. 


\section{Agradecimentos}

Agradeço ao meu orientador, prof. Marcus Wilcox Hemais por ter me ajudado com o tema e no transcorrer das semanas de orientação com muitos conselhos.

Agradeço à minha família por ter feito mais esta jornada ao meu lado.

Agradeço aos amigos que fiz durante o curso de mestrado.

Agradeço enormemente a todos os professores pelos quais passei e dos quais levo para a minha vida uma parte. 


\section{Resumo}

Ferreira, Ricardo José Lodi; Hemais, Marcus Wilcox (Orientador). Consumidores de baixa renda e o seu "Eu” estendido em veículos. Rio de Janeiro, 2017. 70p. Dissertação de Mestrado - Departamento de Administração, Pontifícia Universidade Católica do Rio de Janeiro.

O crescimento do poder aquisitivo da população de baixa renda no Brasil e a consequente alta na demanda por veículos por este estrato da sociedade fizeram crescer o mercado automotivo brasileiro na primeira década dos anos 2000. A próxima relação que esses consumidores passaram a ter com seus veículos tornase, então, o objeto de estudo da presente pesquisa, que tem como principal base teórica a teoria de eu estendido desenvolvida inicialmente por Belk. O autor estipula que objetos de consumo se tornam extensões do "Eu" de consumidores, devido aos simbolismos que carregam e representam. O objetivo final do estudo, portanto, é entender quais são os significados atribuídos por consumidores de baixa renda a seus carros e como os mesmos são representados como uma extensão do "Eu” desses indivíduos. Para isso, foram feitas entrevistas em profundidade com consumidores de baixa renda da cidade do Rio de Janeiro possuidores de carros de passeio. A partir das entrevistas, foi possível a analisar a relação entre esses indivíduos e seus carros como uma extensão de si e, assim, chegar a algumas conclusões.

\section{Palavras-chave}

Consumidor de baixa renda; "Eu” estendido; Veículo; CCT; Consumo. 


\section{Abstract}

Ferreira, Ricardo José Lodi; Hemais, Marcus Wilcox (Advisor). Low income consumers and their extended "Self" in vehicles. Rio de Janeiro, 2017. 70p. Dissertação de Mestrado - Departamento de Administração, Pontifícia Universidade Católica do Rio de Janeiro.

The growth of the purchasing power of the low-income population in Brazil and the consequent increase on the demand for vehicles by this stratum of society made the Brazilian automotive market grow in the first decade of the 2000's. The close relationship that these consumers began to have with their vehicles is the object of the present study, which has as its main theoretical base the theory developed initially by Belk. The author stipulates that consumption objects become extensions of one's self because of the symbolism it carries and represents. The main objective of the study, therefore, is to understand what are the meanings attributed by low-income consumers to their cars and how such vehicles are represented as an extension of the "Self" of these individuals. For this, in-depth interviews were conducted with low-income consumers in the city of Rio de Janeiro who owned cars. Based on the interviews, it was possible to identify the relationship between these individuals and their cars and, thus, come to some conclusions.

\section{Keywords}

Low-income consumer; Extended-self; Vehicles; CCT; Consumption. 


\section{Sumário}

1. Introdução 11

1.1. Objetivo final 13

1.2. Delimitação do estudo $\quad 13$

1.3. Relevância do estudo 14

1.4. Estrutura do trabalho 15

2. Referencial teórico 16

2.1. Consumer Culture Theory e o Eu estendido $\quad 16$

2.2. Simbologia do consumo para os consumidores de baixa renda 34

3. Metodologia $\quad 40$

3.1. Tipo de pesquisa $\quad 40$

3.2. Seleção dos entrevistados $\quad 41$

3.3. Procedimentos de Coleta de Dados 43

3.4. Procedimento de análise de dados 44

3.5. Limitações do método 45

4. Análise e Interpretação dos Resultados 46

4.1. Carro como referência ao passado, à família e como família 46

$\begin{array}{ll}\text { 4.2. Carro como referência ao corpo } & 48\end{array}$

4.3. Referência à posse $\quad 50$

4.4. Referência à condição financeira ou ao status 53

4.5. Referência à disposição e descarte $\quad 55$

5. Conclusão $\quad 57$

5.1. Sugestões para futuros estudos 58

5.2. Limitações do estudo $\quad 59$

5.3. Implicações gerenciais $\quad 60$

6. Referências bibliográficas $\quad 62$

$\begin{array}{ll}\text { Anexo I } & 66\end{array}$

$\begin{array}{ll}\text { Anexo II } & 70\end{array}$ 


\section{Lista de figuras}

Figura 1: Modelo McCracken do Movimento de Significados................................17

Figura 2: Estruturas Comuns de Interesse Teórico................................................22

\section{Lista de tabelas}

Tabela 1: Mal-entendidos quanto à CCT.........................................................20

Tabela 2: Linhas de Pesquisa da CCT...............................................................23

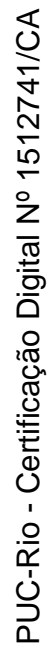

Tabela 3: Casos Especiais de Autoextensão..........................................................31

Tabela 4: Dados Pessoais dos Entrevistados.......................................................42 
Ninguém ignora tudo. Ninguém sabe tudo. Todos nós sabemos alguma coisa. Todos nós ignoramos alguma coisa. Por isso aprendemos sempre.

(Paulo Freire) 


\section{1 \\ Introdução}

A crise financeira mundial deflagrada no final de 2008 trouxe para o mercado automotivo brasileiro consequências desfavoráveis. Até 2010, observouse um crescimento, desde 2003, no consumo interno, conforme apontam Barros e Pedro (2011), fomentado pelo aumento da renda média dos brasileiros e a ascensão social de parcela da população pertencente, especialmente, à classe C. A classe C já foi a grande responsável pelo crescimento da indústria automobilística do Brasil. Em 2012, esse grupo de consumidores ajudou a indústria a alcançar desempenho recorde (SILVA, 2015).

É comum que consumidores de baixa renda consumam itens em sua cesta de compras por meio de pagamentos parcelados a perder de vista. Esse é o chamado "efeito Casas Bahia”, que ocorre quando o consumidor ajusta o número de prestações ao valor que acredita ser o ideal para pagar mensalmente (INSTITUTO DE DESENVOLVIMENTO DO VAREJO, 2009). Tal prática, aliada ao crescimento do poder aquisitivo das camadas de baixa renda, ajudou a aumentar as vendas do setor automotivo, pois famílias desse estrato da população passaram a adquirir o tão sonhado carro zero através de parcelamentos de até 72 meses - há planos de consórcios de até 120 meses. O consumidor, em muitos casos, vê a aquisição de um veículo como um símbolo de status perante seus pares. Dessa forma, admite prestações que podem chegar a $30 \%$ da sua renda mensal. Corroborando com o mencionado, Vieira (2014, p. 24) disse:

Hoje, prevalece a certeza de que andar de ônibus ou de trem é coisa de pobre. Quem consegue juntar algum dinheiro trata logo de comprar um carro. Mesmo que ele passe a maior parte do tempo na garagem ou engarrafado. O que importa é o símbolo de status, a ideia de que se está subindo na vida.

No entanto, o que se tem visto nos últimos anos é a queda do mercado automotivo com especial atenção ao público de baixa renda. Faz-se necessário explicitar aqui que o público de baixa renda é, necessariamente, aquele pertencente às classes $\mathrm{C}, \mathrm{D}$ e E conforme o critério de classificação de classes sociais estabelecido pelo IBGE (Instituto Brasileiro de Geografia e Estatística). 
Segundo Laguna (2016), a perda de renda, o endividamento das famílias, os preços altos e as dificuldades em adquirir crédito foram determinantes para minarem o poder de compra dos brasileiros, transformando o mercado de automóveis em um ambiente voltado ao público de mais alta renda, pois as financeiras, bancos e afins passaram a exigir mais dos compradores quando da submissão de seu cadastro para consecução do crédito para a compra do almejado veículo. Além disso, ainda conforme Laguna (2016), as instituições de crédito passaram a limitar o percentual da renda do consumidor a ser comprometida com a compra do carro zero, aumentaram as taxas de juros e, também, reduziram o prazo médio desse financiamento.

Diante de um cenário de recessão no mercado automotivo de veículos novos, volta a crescer o comércio de veículos usados (SILVÉRIO, 2016). Isso tem beneficiado a indústria de autopeças, pois as famílias acabam gastando mais na manutenção de seus carros do que em adquirir um novo (SARAIVA, 2016). Segundo Saraiva (2016), o aumento da demanda por serviços de manutenção dos veículos tem crescido mais de $26 \%$, enquanto - na contramão - as vendas de veículos novos têm caído praticamente na mesma proporção.

A relação próxima entre consumidores e automóveis leva autores em marketing a identificarem que o objeto passa a se tornar uma extensão do "eu” dos indivíduos (PONCHIO; STREHLAU, 2011; RAMALHO; AYROSA, 2009), conforme preconizado por Belk (1988). Para Belk (1988) o “eu” estendido é tudo aquilo ou todo aquele com o qual o indivíduo guarde uma estreita relação. Desta forma, percebe-se grande relevância para o indivíduo a ponto de sentir aquele ou aquilo como parte de si. Seguindo nesta linha, são abordados os significados do carro para a baixa renda partindo-se de um mundo culturalmente constituído, conforme McCracken (2003) abordando-se os rituais de transferência de significados dos bens aos indivíduos e partindo-se da cultura do consumidor, segundo preconizam Arnould e Thompson (2005), através da CCT (Consumer Culture Theory).

A categoria de produto automóvel e o "eu” estendido já ensejaram estudos como Ponchio e Strehlau (2011), Ramalho e Ayrosa (2009). Todavia, tais estudos não esclarecem como essa relação se dá quando o consumidor em questão é o de baixa renda. 


\section{1}

\section{Objetivo final}

O presente estudo tem como objetivo final entender quais são os significados atribuídos por consumidores de baixa renda a seus carros e como tais veículos são representados como uma extensão do self desses indivíduos.

Para isso, foram feitas 20 entrevistas em profundidade com consumidores de baixa renda da cidade do Rio de Janeiro possuidores de veículos.

\section{2}

\section{Delimitação do estudo}

De forma a deixar claro quais são os pontos que a presente pesquisa pretende cobrir, são feitas algumas delimitações do estudo, entre elas sobre sua lente de análise teórica, o público a ser estudado e o objeto ao qual deseja-se entender a relação com o consumidor estudado.

A linha de pesquisa adotada para este trabalho segue aquela desenvolvida inicialmente por Belk (1988), no que diz respeito à maneira como objetos de consumo se tornam extensões do eu de consumidores. Pode-se dizer que a extensão do Eu se dá em níveis haja vista a possibilidade de autoextensão em direções distintas - objetos, lugares ou pessoas. Deste modo, ainda que outros autores (RAPOPORT, 1981; ATKIN, 1981; FELDMAN, 1979) trabalhem com quatro, sete ou onze níveis do Eu, respectivamente, trabalhar-se-á nesta pesquisa com os quatro níveis elencados por Belk (1988): individual, família, comunidade e grupo, com especial atenção ao nível individual como objeto de trabalho desta pesquisa.

Embora se pudesse enveredar por um caminho mais amplo da pesquisa aqui proposta, no que tange ao público-alvo este estudo está delimitado aos consumidores de baixa renda de veículos na cidade do Rio de Janeiro. Entende-se como consumidores de baixa renda aqueles pertencentes às classes C, D e E, definidos a partir do critério de classificação de classes sociais dado pelo Instituto Brasileiro de Geografia e Estatística (IBGE), conforme o anexo II. 
De acordo com o Código de Trânsito Brasileiro (CTB), automóvel é: "veículo automotor destinado ao transporte de passageiros, com capacidade para até oito pessoas, exclusive o condutor” (1997, p. 55). Assim, o foco desse trabalho será em entender a relação de consumidores de baixa renda com veículos de passeio, ou seja, aqueles prioritariamente voltados ao uso diário no deslocamento casa-trabalho e semelhantes ou ao uso familiar. Não se enquadram para análise, portanto, camionetas, caminhonetes e veículos utilitários, pois estes têm como característica adicional o transporte de cargas, bem como motocicletas e similares ou quaisquer outros veículos que não estejam enquadrados na definição acima citada pelo CTB.

\section{3}

\section{Relevância do estudo}

O presente estudo possui relevância em duas principais frentes, a acadêmica e a empresarial.

O estudo é justificado pelo grau de importância adquirido pelas classes de baixa renda em face do seu crescimento, nos últimos anos, no Brasil. Segundo Casotti e Suarez: “como país emergente, o Brasil possui grande parte da população ainda em processo de inclusão no mercado de consumo de diversas categorias de produtos e serviços” (2016, p. 358).

A relevância do presente estudo está evidenciada na evolução de diversos setores da economia voltados aos consumidores de baixa renda, notadamente o setor automotivo brasileiro, com forte expansão desde o início dos anos 2000 até 2012, inclusive.

Academicamente, sua relevância reside no fato de haverem estudos que versem tanto sobre o “eu” estendido em carros - por exemplo, Ponchio e Strehlau (2011), Ramalho e Ayrosa (2009) - quanto estudos sobre os indivíduos de baixa renda - por exemplo, Barros (2007) e Castilhos (2007) não tendo sido encontrados estudos associando "eu" estendido em carros na baixa renda. Em outras palavras, há estudos sobre self e carros, porém nenhum com automóveis, self e indivíduos de baixa renda.

Do ponto de vista empresarial, este estudo se justifica, por trazer knowhow a ser aplicado no mercado através do maior conhecimento acerca do 
consumidor de baixa renda cujas preferências, anseios e afins não são - na sua maioria - bem conhecidos o que poderá gerar novas formas de abordagens a estes consumidores e, consequente, incremento nas vendas.

\section{4}

\section{Estrutura do trabalho}

Além do capítulo introdutório, o presente estudo está estruturado em mais quatro capítulos.

No segundo capítulo, será discutido o referencial teórico. Nele serão abordados a CCT (Consumer Culture Theory), o conceito do "eu” estendido e a simbologia do consumo para os consumidores de baixa renda.

No terceiro capítulo, será discutida a metodologia do estudo. Serão abordados o método escolhido para este estudo e como foi conduzido todo o processo até se chegar ao mais importante capítulo do presente estudo.

No quarto capítulo, será apresentada a análise e interpretação dos resultados. Nele são feitas inferências acerca do que foi apurado durante o estudo.

Por fim, no quinto capítulo, são feitos os comentários finais da pesquisa com sugestões para futuros estudos e apresentação das limitações do estudo. 


\section{2}

\section{Referencial teórico}

Neste capítulo, são discutidos aspectos teóricos e estudos relacionados ao tema aqui pesquisado. Esta seção está dividida em duas partes que abordam, respectivamente: a CCT (Consumer Culture Theory) e o “eu” estendido, para contextualizar o problema de pesquisa; e a simbologia do consumo para os consumidores de baixa renda.

\section{1}

\section{Consumer Culture Theory e o Eu estendido}

A sociedade, da forma como se apresenta atualmente, é reflexo do movimento de significados vindos de um mundo culturalmente constituído mundo de experiências cotidianas - em direção ao indivíduo. Tal movimento apresenta como momentos a passagem dos significados do mundo aos bens e, posteriormente, destes aos indivíduos, momentos esses dotados de seus sistemas e rituais (MCCRACKEN, 2003), conforme a figura 1 (modelo McCracken). De outra forma, pode-se dizer que o mundo é resultado das interações entre indivíduos, cada um com seu conjunto de crenças, valores e, portanto, é socialmente construído (DOUGLAS; ISHERWOOD; 2009). 
Movimento de significados

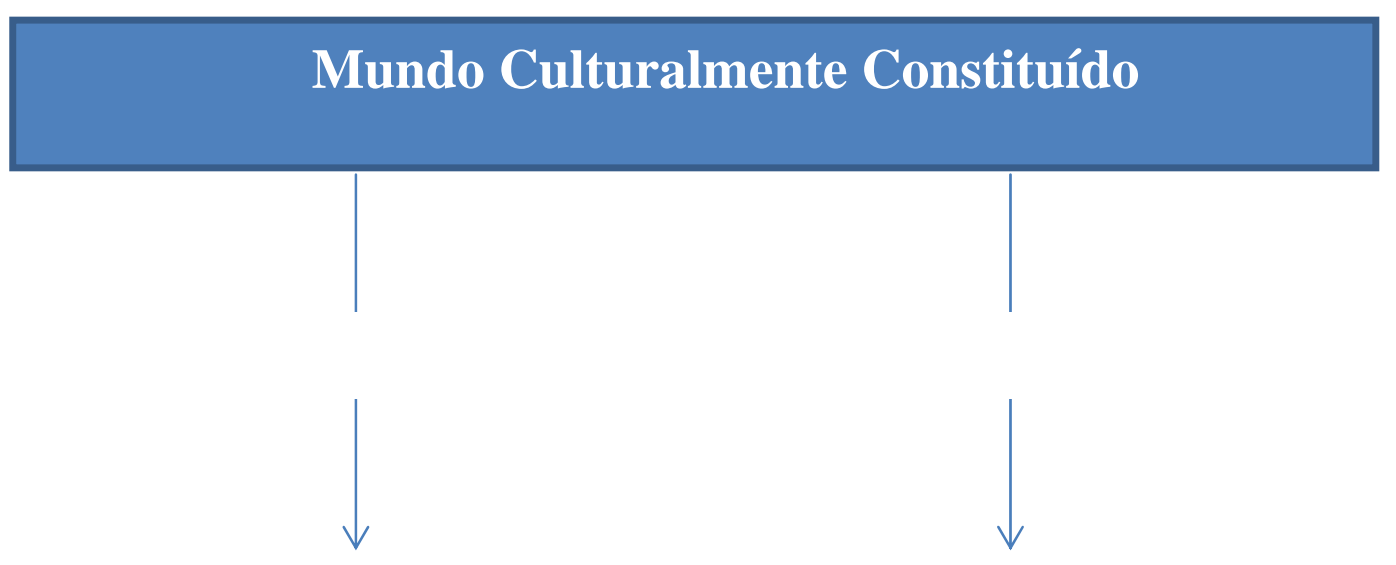

\section{Bens de Consumo}

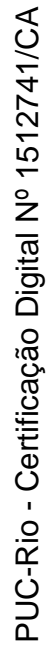

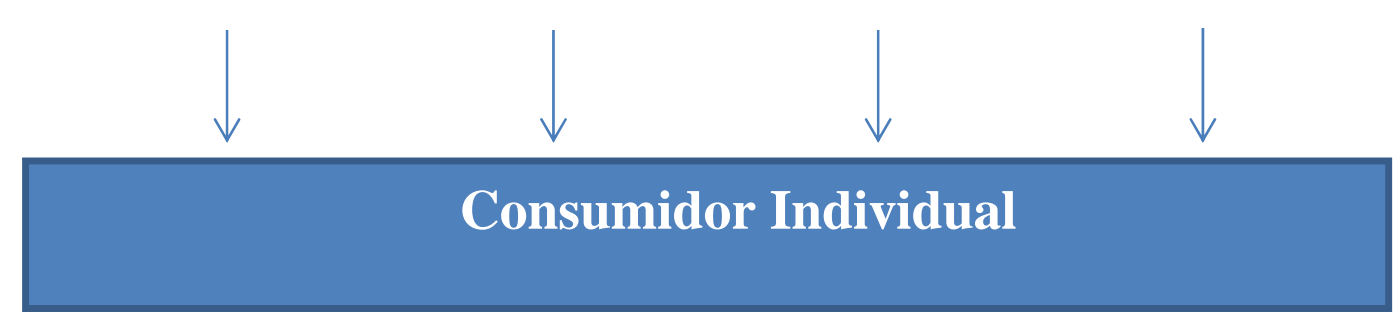

\section{Legenda:}

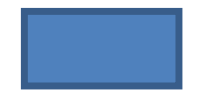

Localização do Significado

Instrumentos de Transferência de Significado

Figura 1: Modelo McCracken do Movimento de Significados.

Fonte: McCracken (2003), adaptado pelo autor.

Para entender-se o mundo culturalmente constituído, é necessário mencionar o que vem a ser cultura. Cultura, segundo Douglas e Isherwood (2009, p. 44), é “essencialmente um conjunto de princípios”. Além disso, Douglas e Isherwood (2009, p. 125) expõem que: 
O consumo físico permite a prova, o teste ou a demonstração de que a experiência em questão é viável. Mas o argumento antropológico insiste em que, de longe, a maior utilidade não está na prova, mas no compartilhamento dos nomes que foram aprendidos e classificados. Isso é cultura.

Para McCracken (2003, p. 101), “a cultura constitui o mundo suprindo-o com significado”. Em outras palavras, a necessidade a ser suprida é simbólica. O autor ainda estabelece duas maneiras de conformação do mundo pela cultura. A primeira em que a cultura funcionaria como lente através da qual o mundo seria visto. A segunda seria como a atividade humana transformaria o mundo.

Corroborando a ideia de McCracken (2003), Belk (1988) afirma que não se pode compreender o consumidor sem antes compreenderem-se os significados por ele atribuídos às suas posses. Para Rocha (2009, p. 8):

Os bens são investidos de valores socialmente utilizados para expressar categorias e princípios, cultivar ideias, fixar e sustentar estilos de vida, enfrentar mudanças ou criar permanências.

Douglas e Isherwood (2009, p. 43) afirmam que "os bens são como bandeiras”. McCracken (2003) expõe que o significado se transfere do bem ao indivíduo através de ações simbólicas também - e mais! - conhecidas por rituais. Para Douglas e Isherwood (2009, p. 112), “os rituais servem para conter a flutuação dos significados” e, também, “os rituais mais eficazes usam coisas materiais”. Nesse sentido, os autores ainda afirmam que uma vida sem rituais é sem significados definidos e, possivelmente, sem lembranças. Assim, o que se pode apreender é que para esses autores os rituais são o caminho para tornar-se a cultura tangível.

A transferência de significado se dá pelos rituais: de troca, de posse, de arrumação e de despojamento. São todos meios de categorização - ou recategorização - coletiva ou individual configurando potentes ferramentas de significação - ou ressignificação (MCCRACKEN, 2003). Belk (1988) ainda expõe que só é considerado estendido o Eu quando este guarda estreita relação com a posse, de modo a formar significados para o indivíduo. De outra forma, Douglas e Isherwood (2009) afirmam que os bens escolhidos são fruto de uma constante repadronização de comportamentos. Para os autores, "os bens são, portanto, a parte visível da cultura” (2009, p. 114). Pode-se dizer, então, que as decisões de consumo são determinadas pela cultura. Belk (1988) ainda indica que 
os indivíduos constroem suas identidades sobre símbolos que expressam suas preferências de consumo. Em outras palavras, há uma identificação do consumidor com a posse, de forma que ele percebe e até ostenta as qualidades vindas de sua posse (MCCRACKEN, 2003). Segundo McCracken (2003, p. 116), “é desta maneira, talvez, que os indivíduos criam um 'mundo de bens' pessoal, que reflete suas próprias experiências e conceitos de si e do mundo”.

Dito que a sociedade atual é resultado de um mundo culturalmente constituído e definido o que é cultura, faz-se necessário definir-se consumo. Segundo Douglas e Isherwood (2009, p. 102), consumo é “um uso de posses materiais que está além do comércio e é livre dentro da lei”. De outra forma, os autores afirmam que "a função essencial do consumo é sua capacidade de dar sentido” (2009, p. 106). O consumo é uma forma de redefinição contínua das categorias sociais. Por fim, Douglas e Isherwood (2009, p. 115-116) afirmam:

O consumo usa os bens para tornar firme e visível um conjunto particular de julgamentos nos processos fluidos de classificar pessoas e eventos... o indivíduo usa o consumo para dizer alguma coisa sobre si mesmo, sua família, sua localidade, seja na cidade ou no campo, nas férias ou em casa.

A pesquisa do consumidor nos últimos anos tem proporcionado diversos outros estudos direcionados aos aspectos sociocultural, experiencial, simbólico e ideológico do consumo. De acordo com Arnould e Thompson (2005), após anos de pesquisa e ênfase em metodologias diversas, chegou-se ao que se convencionou chamar de CCT (Consumer Culture Theory).

A CCT não é uma área de estudo ou uma teoria independente. Na verdade, a CCT agrega diversas perspectivas que transitam na relação entre consumidores e mercado. De forma similar, pode-se dizer que a CCT visa entender os comportamentos dos consumidores em consequência de seus valores, crenças e, obviamente, cultura. Ou, conforme Arnould e Thompson (2005, p. 869) expõem: “CCT explora a distribuição heterogênea de significados e a multiplicidade de agrupamentos culturais sobrepostos que existem dentro do mais amplo quadro sócio histórico da globalização e do capitalismo de mercado”. Segundo Casotti e Suarez (2016), a CCT tem como suas preocupações centrais os significados, as influências sócio históricas e as dinâmicas sociais através das quais são moldadas experiências e identidades dos consumidores em diversos contextos. Ou, de outro 
modo, a CCT recebe participação de autores de outras áreas, complementares, das ciências sociais.

Segundo Arnould e Thompson (2005), como os pesquisadores de consumidores ficaram com uma lacuna no que concerne a treinamentos e metodologias mais comuns à CCT, houve mal-entendidos sobre o que é a CCT. O primeiro desses mal-entendidos foi com relação a o quê estudam os pesquisadores da CCT. Nesse sentido, esclareceu-se que, ao contrário do que se pensava, tais pesquisadores estudam em contextos de consumo e, não, os contextos de consumo. O segundo mal-entendido foi com relação às diferenças metodológicas. Aqui, o senso comum levava a crer que a CCT tinha preferência por dados qualitativos. É bem verdade que metodologias qualitativas tiveram importância central para o desenvolvimento da CCT dado que buscam abordar as questões experiencial e sociocultural do consumo. Sendo assim, eram mais fiéis a tais abordagens os métodos qualitativos. A CCT, entretanto, não limita seus pesquisadores, permitindo um pluralismo metodológico sempre que se faz necessário. O terceiro mal-entendido se deu por conta da suposta irrelevância que foi atribuída à CCT dado seu escopo experiencial e sociocultural, além do desenvolvimento de uma disciplina autônoma, não percebida como de base nem mesmo como subespecialidade de publicidade, tampouco marketing (ver Tabela $1)$.

Tabela 1: Mal-entendidos quanto à CCT.

\begin{tabular}{|l|l|}
\hline $\mathbf{1}^{\mathbf{0}}$ ) O que estudam? & Estudam em contextos de consumo. \\
\hline $\mathbf{2}^{\mathbf{0}}$ ) Quais metodologias? & Pluralismo metodológico. \\
\hline $\mathbf{3}^{\mathbf{0}}$ ) Qual a relevância da CCT? & $\begin{array}{l}\text { Sua autonomia, interdisciplinaridade com foco } \\
\text { experiencial e sociocultural. }\end{array}$ \\
\hline
\end{tabular}

Fonte: Elaborado pelo autor com base em Arnould e Thompson (2005).

Como dito anteriormente, a CCT visa entender os comportamentos dos consumidores em decorrência de seus valores, crenças e cultura. De outra forma, a CCT busca entender o conjunto de significados atribuídos pelos consumidores a tudo aquilo ou todo aquele com quê se relacionam. Além disso, procura entender como tais significados, por vezes, podem ser retrabalhados no intuito de nova identificação. Diferentemente do mainstream positivista da pesquisa sobre 
consumo, a CCT é uma abordagem interpretativista. Nesse sentido, para Souza et al. (2013, p. 386):

A CCT trata dos aspectos produtivos do consumo, da maneira como os indivíduos criam e transformam ativamente os significados simbólicos presentes em propagandas, marcas, no mercado ou em bens materiais, a fim de exprimir suas particularidades pessoais e sociais.

Conforme Souza et al. (2013) indicam, a CCT surge em um momento em que as relações sociais se dão prioritariamente baseadas na ética do consumo e não mais sob a égide da ética e dos bons costumes - valores, ideais e cultura que formam a identidade do indivíduo. Ou, de acordo com o que expõem Douglas e Isherwood (2009, p. 110): “nenhum ser humano existe senão fixado na cultura de sua época e lugar”. A CCT está organizada em quatro linhas de pesquisa: culturas de mercado; padronização sócio histórica do consumo; ideologias do mercado massivamente mediadas e estratégias interpretativas dos consumidores; e projetos de identidade do consumidor (ARNOULD; THOMPSON, 2005), conforme a figura 2. Nesta dissertação, o foco será a linha de pesquisa de projetos de identidade do consumidor. Sendo assim, as demais serão somente sumarizadas na Tabela 2, no intuito de se manter a atenção sobre a linha que mais interessa neste trabalho. 
“Glocalização” e as vias globais

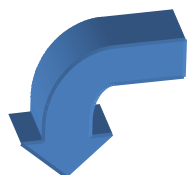

\section{A padronização sócio histórica do consumo:}

A modelação do consumo se dá por classes, etnias, gêneros, e outras categorias sociais, consumo sob condições de recursos culturais atenuados, a institucionalização e reprodução das relações de poder através de hierarquias.socioeconômicas.
Tensões estruturais

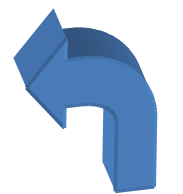

\section{Culturas de mercado:}

Dinâmicas

socioculturais envolvidas em comunidades de marcas, de fãs, microculturas de consumidores, subculturas de consumo, tribos de consumidores, mercado como mediador das interações sociais e relacionamentos sociais.

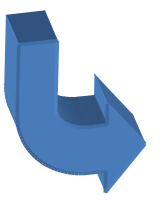

Redes mediadas pelo mercado e consumo incorporado

\section{Ideologias de mercado massivamente mediadas e} estratégias interpretativas dos consumidores:

Representações discursiva, imagética e material das ideologias consumeristas no mercado; uso ativo da mídia e ações contrárias aos códigos hegemônicos; a dinâmica da cooptação corporativa; influências da globalização na mídia e no consumo.

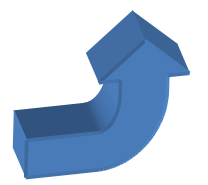

Modelação ideológica

de identidade,

objetivos e desejos dos consumidores

Figura 2: Estruturas Comuns de Interesse Teórico.

Fonte: Arnould e Thompson (2007), adaptado pelo autor. 
Tabela 2: Linhas de pesquisa da CCT.

\begin{tabular}{|c|c|}
\hline 1') Culturas de mercado & $\begin{array}{l}\text { O objetivo é saber como a atividade e interpretação culturais são reconfiguradas pela } \\
\text { prática habitual de consumo e vice-versa. Para Souza et al. (2013), os consumidores } \\
\text { são produtores de cultura em vez de portadores dela. }\end{array}$ \\
\hline $\begin{array}{l}\text { 2a) Padronização sócio } \\
\text { histórica do consumo }\end{array}$ & $\begin{array}{l}\text { Nesta linha busca-se entender o que é e como é constituída e sustentada a sociedade } \\
\text { do consumo. Para Arnould e Thompson (2005, p. 874), são abordadas "as estruturas } \\
\text { institucionais e sociais que influenciam sistematicamente o consumo, como classe, } \\
\text { comunidade, etnia e gênero". }\end{array}$ \\
\hline $\begin{array}{l}3^{\text {a)}) ~ I d e o l o g i a s ~ d o ~ m e r c a d o ~} \\
\text { massivamente mediadas e } \\
\text { estratégias interpretativas dos } \\
\text { consumidores }\end{array}$ & $\begin{array}{l}\text { Nesta linha de pesquisa, consumidores submetidos às mensagens transmitidas pelas } \\
\text { mídias de massa e, com base no seu entendimento, formulam respostas. Em outras } \\
\text { palavras, cada grupo de consumidores receberá com maior ou menor resistência as } \\
\text { mensagens das mídias de massa - e até se sentirá pressionado por elas - na medida } \\
\text { do "background" de seus consumidores integrantes. Aqui os consumidores são } \\
\text { concebidos como agentes interpretativos criando significados. }\end{array}$ \\
\hline $\begin{array}{l}\left.4^{\mathrm{a}}\right) \text { Projetos de identidade do } \\
\text { consumidor }\end{array}$ & $\begin{array}{l}\text { Nesta linha de pesquisa os consumidores são identificadores e formadores de } \\
\text { identidades baseados nas representações do Eu em decorrência dos significados por } \\
\text { eles atribuídos às posses. }\end{array}$ \\
\hline
\end{tabular}


Já com relação à linha de pesquisa relativa aos projetos de identidade do consumidor - na qual o Eu estendido é tratado -, Arnould e Thompson (2005, p. 871) afirmam que "os consumidores são concebidos como identificadores e formadores de identidades”. Isto ocorre, pois, os consumidores podem almejar algo pela própria falta de recursos, o que os levaria à construção de narrativas e identidades baseadas em suas carências materiais, pessoais ou afetivas como justificativa. De outra forma, as narrativas e identidades formadas às quais se referem Arnould e Thompson (2005) são representações do Eu dos consumidores baseadas nos significados por eles atribuídos.

Além disso, Arnould e Thompson (2005, p. 871) afirmam que “a relação entre os projetos de identidade dos consumidores e a influência estruturante do mercado” produzem posições de consumo as quais os consumidores podem escolher. Sendo assim, conforme Souza et al. (2013), os consumidores constroem e reconstroem suas identidades influenciados por causas internas e externas mercado ou outras pessoas - e, desta forma, estendem seu Eu.

Neste momento, torna-se importante uma diferenciação entre o Eu e o Eu estendido (self estendido). Para Belk (1988), o Eu é a identidade do indivíduo perante a sociedade, enquanto o Eu estendido é tudo aquilo ou todo aquele considerado pelo indivíduo como parte de si. Para Ponchio e Strehlau (2011, p. 301):

O 'eu’ pode ser expandido por meio da incorporação de objetos, pessoas e ideias, e possui múltiplas camadas... os objetos associados ao self estendido permitem que as pessoas definam o seu 'eu' usando objetos que mais bem se identificam com as suas atitudes, crenças e sua identidade pessoal.

Assim, o Eu estendido seria a soma do Eu com as posses fossem essas, objetos, pessoas ou sentimentos.

Belk (1988) busca o entendimento acerca das reações calcadas nos valores simbólicos atribuídos aos bens possuídos pelos consumidores. Neste sentido, o autor expõe a dificuldade ou mesmo a impossibilidade de se entender o consumidor sem, primeiramente, entender-se os significados por este atribuídos a seus pertences. Nesta linha, afirmam Douglas e Isherwood (2009, p. 41) que "nada tem valor por si, o valor de cada coisa depende de todo o espaço de significação em que os objetos são usados depois de comprados”. 
Uma importante constatação de Belk (1988) é a de que consideramos nossas posses como partes de nós mesmos. Em outras palavras, o autor fornece uma ideia de sua corrente de pensamento dizendo que: "nós somos o que nós temos é, talvez, a mais elementar e potente verdade do comportamento do consumidor” (BELK, 1988, p. 139).

De outro modo, Belk (2003) indica que o estilo, as cores, a condição e até mesmo a combinação de bens que estejam sendo usados podem dar dicas, levando a inferências a respeito dos outros. Tuan (1980) corrobora esta ideia afirmando que a noção que temos de nós mesmos é frágil, de tal forma que precisamos de apoio, que é conseguido ao ter e possuir bens, pois na maioria das vezes ou para a maioria das pessoas com quem nos relacionamos, nós somos o que temos.

Belk (1988) coloca como possível definição de posses as coisas que chamamos de nossas e, sendo assim, estaria dizendo de forma sucinta que somos a soma de nossas posses. Deste modo, Belk revela a extensão do "Eu" do consumidor através de comportamentos assumidos que transbordam a identidade da pessoa humana em vários significados, que decorrem em grande parte da cultura - de todas as experiências vividas - por tal consumidor e que o leva a adotar seus bens como parte de si mesmo.

Belk (1989) afirma que a percepção tanto do Eu, quanto do Eu estendido, é influenciada pelos efeitos da cultura, o que explica porque uma posse importa muito a um indivíduo, enquanto a outro esta não exerce influência alguma. O que se quer dizer aqui é que, conscientemente ou não, com ou sem intenção, tendemos a considerar nossas posses partes de nós enquanto possuidores ou consumidores: “automóveis são adquiridos como uma segunda pele na qual os outros podem nos ver” (BELK, 1988, p. 151).

De outra forma, consideramos uma extensão de nós tudo aquilo que tratamos como se tratássemos de nós mesmos. Assim, consideramos extensões de nós - e, portanto, nosso Eu estendido - nossa fama, nossos filhos, o trabalho por nós realizado além de nossos corpos e produtos que nos pertençam. Porém, Belk (1989) ressalta que nem tudo que é importante para um indivíduo faz parte do seu Eu estendido. Em outras palavras, o autor busca dar maior relevo ao que realmente importa ao indivíduo, aquilo sem o quê ele se sentiria menor ou que despertaria nele outro sentimento parecido. 
Para Belk (1988), talvez a mais simples e potente verdade acerca do comportamento do consumidor seja a de que todos são reflexo daquilo que têm. Pode-se dizer, também, que a perda em si revela comportamentos diferentes dos revelados pela posse. Assim, órgãos, entes queridos ou mesmo bens perdidos em acidentes, roubos ou furtos são motivos de mudanças no comportamento dos consumidores. Isto ocorre pois trazem à tona o sentimento de perda de algo estimado e maior do que, por exemplo, um mero objeto, levando em consideração as memórias a ele atreladas. Em suma, é um sentimento de violação não somente da propriedade pessoal e particular - no que tange aos objetos - como também uma violação pessoal - no que concerne aos órgãos ou entes queridos. É, enfim, uma perda de parte significativa de si próprio.

Em relação à extensão do próprio Eu, Belk (1988) menciona o sentimento de perda de proprietários de veículos, cuja integridade é tão ou mais importante que a do próprio corpo. Neste sentido, o autor revela o desejo de restauração, que há em cada um dos proprietários, da aparência anterior do veículo, como se fosse parte de si. Antes disso, chama a atenção para o zelo exagerado de alguns proprietários com seus veículos, o que, novamente, remete à extensão do Eu próprio. Nesse sentido, Ponchio e Strehlau (2011) afirmam que é proporcional a importância dada pelo Eu estendido ao objeto e o cuidado ao mesmo dedicado, cuidado esse que pode ser em forma de zelo, manutenção ou, ainda, melhorias, como no estudo sobre carros “tunados” de Ramalho e Ayrosa (2009).

Belk (1988) apresenta as funções do Eu estendido como sendo o ter, o fazer e o ser. Tais funções são abordadas mostrando o quão relacionadas entre si elas são. Nessas funções, corrobora-se a ideia de possuir para ser, mas ao mesmo tempo tal ideia é questionada, pois: se somos o que temos, ao perdermos o que temos deixaríamos de ser quem, realmente, somos? Na verdade, o autor não busca resposta para este questionamento, mas deixa claro o quão abstrato pode ser reconhecer as pessoas pelas suas posses, haja vista a possibilidade de perdê-las, em algum momento.

Quando Belk (1988) analisa o Eu versus os Outros, onde, para as crianças, ter menos que as outras significa ter menos amor ou respeito que as outras, é criada uma rivalidade: uma rivalidade de bens. Nessa rivalidade de bens, as crianças podem apresentar comportamentos peculiares aos adultos, tais como disputas de poder, prestígio ou mesmo pelas posses. Assim, pode-se intuir que, tal 
como se constatou com as crianças, os adultos podem - através de seus veículos disputar poder, prestígio - status! - pela posse de um veículo.

Posteriormente, Belk (1988) analisa as diferenças entre o Eu estendido na adolescência e na idade adulta. Os adolescentes dão ênfase maior às posses, ao enaltecimento das características e habilidades individuais, além da importância dada aos automóveis e roupas como forma de obtenção de prestígio. Os adultos entre 40 e 50 anos justificam suas posses pelo poder social e o status. Ademais, casais mais novos tendem a valorizar mais as posses que refletem objetivos e planos futuros, enquanto que os casais mais maduros tendem a valorizar objetos e experiências conjuntas. De forma semelhante, Belk (1985, p. 269) afirma:

Adolescentes devem valorizar mais as atividades que os objetos, e pessoas mais velhas devem ser menos egoístas, dado que seu materialismo é essencialmente focado em lembranças simbólicas do passado.

Quanto às posses e o sentimento de passado, as memórias são privilegiadas em detrimento das características funcionais dos objetos, tendo por significado a perpetuação de um ciclo familiar. A soma de bens tangíveis e intangíveis constitui um patrimônio, por vezes, imaterial, que pode ser editado na memória das famílias e da sociedade formando uma fotografia de seus "Eus". Nesse sentido, o estudo de Ponchio e Strehlau (2011), que mostra o Eu estendido sobre os automóveis clássicos, evidencia que estes consumidores "associam boas lembranças aos seus carros clássicos, consideram os carros clássicos como parte de suas famílias” (p. 305). Tais associações se revelam nostálgicas e, portanto, uma confirmação do constante processo de construção e reconstrução dos “Eus”.

Os processos chamados por Belk (1988) de processos de autoextensão contemplam casos em que se tem controle - ou domínio - sobre as posses voltadas ao uso pessoal, como um carro. Nesse ponto, poder-se-ia incluir a autonomia das pessoas, pois quanto mais capazes de fazer o que querem ou o que devem com independência, maior a autoextensão alcançada. O ato de doar algo a alguém também pode representar um caso de autoextensão, pois quem recebe uma doação simplesmente recebe algo escolhido por outra pessoa. Assim, o ato de doar significa a autoextensão do doador (MCCRAKEN, 1986).

Ainda nessa linha de raciocínio, o fato de ser o criador, o idealizador de algo constituiria a autoextensão do criador. O criador do objeto se estende 
analogamente ao que ocorre na relação entre doador e destinatário. O dinheiro - e seu poder aquisitivo - pode, de outra forma, representar a autoextensão do indivíduo. De outro modo, o Eu pode ser estendido através do conhecimento que se vier a formar acerca de determinada posse. Aqui são consideradas partes do seu Eu - portanto, extensões de si próprio - as relações humanas, as relações com lugares ou objetos. Além disso, o Eu só é considerado estendido quando guarda uma relação estreita com o outro - objeto, lugar ou pessoa -, de modo a formar significados para a pessoa, memórias. Os processos de autoextensão descritos até aqui - controle/domínio, criação e conhecimento - são processos ativos e intencionais. Porém, há uma forma que pode ou não ser ativa ou intencional: a contaminação.

A contaminação consiste no fato de que uma pessoa pode ser intencionalmente ou não obrigada a carregar o Eu de outrem. Um exemplo disso são os casos de estupro. Note que aqui não se está mencionando o aspecto médico do ocorrido, tal como uma contaminação por vírus ou bactérias, pois a vítima carrega consigo a marca indelével do ato praticado contra a sua vontade. Outro exemplo de contaminação pode ser visto no canibalismo. Nesse caso, a contaminação fica caracterizada quando pessoas tentam se parecer com as demais de um grupo. Esse é um caso de contaminação intencional. Entretanto, há outras formas de contaminação, que podem ser citadas como o compartilhamento de bens tais como roupas ou utensílios como copos ou mesmo o uso de roupas de segunda mão.

Como são possíveis extensões do Eu em direções distintas - objetos, lugares ou pessoas -, pode-se dizer que a extensão do Eu se dá em níveis. Assim, mesmo que outros autores (RAPOPORT, 1981; ATKIN, 1981; FELDMAN, 1979) trabalhem com quatro, sete ou onze níveis do Eu, respectivamente, trabalhar-se-á nesta pesquisa com os quatro níveis elencados por Belk (1988): individual, família, comunidade e grupo, com especial atenção ao nível individual como objeto de trabalho desta pesquisa.

Fazendo uma separação entre o nível individual e os demais - que são coletivos - pode-se dizer que o indivíduo constrói sua identidade sobre símbolos que expressam seu próprio consumo, enquanto nos demais níveis a identidade é construída através do compartilhamento de símbolos entre os membros da família, comunidade ou grupo. Esses símbolos formarão o Eu individual ou o coletivo. 
Assim, são exemplos de símbolos da autoextensão do indivíduo: carros, maquiagem, joias, acessórios, tais como canetas, óculos, isto, pois são definidores da identidade individual. Passando ao nível da família, pode-se dizer que a casa em si, sua mobília ou mesmo o estilo de decoração empregado nela constitui uma forma de identificar esta família e, portanto, diferenciá-la - e a seus membros perante as demais famílias de uma comunidade. Tomando-se por comunidade os residentes de uma rua, poder-se-ia dizer que a identidade é dada pela ornamentação externa das casas dessa rua em contraste com as demais ruas de um bairro. Assim, os moradores constituiriam uma identidade particular, única, em relação às demais moradias.

Seguindo nos níveis de autoextensão, chega-se ao nível de grupo. Esse nível é identificado por características comuns aos seus membros, tanto de comportamento, quanto de posses, significando uma possível transição do seu Eu, no intuito de se adequar ao grupo em questão. Isto pois, segundo Douglas e Isherwood (2009, p. 105), os bens “são necessários para dar visibilidade”. De outra forma, os mesmos autores afirmam que "os bens são dotados de valor pela concordância dos outros consumidores” (2009, p. 123). Assim, os indivíduos são mais propensos a se vincularem a objetos que sejam mais importantes tanto para a identidade individual quanto do grupo (BELK, 1989). Desta forma, para Schouten (1991, p. 421), “uma transição de identidade começa com a separação de algum papel, relação ou outro componente-chave do eu estendido”. Nesse sentido, os grupos podem ser caracterizados pela sua forma - distinta dos demais - de se vestir ou ainda os tipos de corte de cabelo usados ou mesmo os bens em comum. Em síntese, segundo Douglas e Isherwood (2009, p. 40): “o consumo é um conjunto de rituais recíprocos”.

Segundo Schouten e McAlexander (1995) - a respeito dos proprietários de motocicletas Harley-Davidson -, a entrada e, mesmo, a mobilidade dentro do grupo constituem uma paulatina transformação do Eu de cada proprietário. Assim, os autores mostram que os proprietários de "Harleys” aderem ao estilo do grupo mesmo contrariando algumas de suas preferências. Além disso, mostram também que os proprietários de “Harleys” buscam reconhecimento, diferenciação, status.

Também, não se poderia deixar de citar como um grupo aquele de proprietários de automóveis clássicos, conforme o estudo de Ponchio e Strehlau (2011). De outro modo, Beck et al. (2009), afirmam que os objetos associados ao 
Eu estendido ajudam as pessoas a se autoconhecerem melhor possibilitando a inclusão de objetos que melhor representem seus valores, crenças, atitudes e identidade. Assim, conforme Schouten (1991, p.421-422) indica:

A natureza específica do eu possível das pessoas é afetada por muitos fatores individuais e socioculturais. Os possíveis esquemas de si mesmos parecem ser compostos de aspectos de eus passados e de vários modelos de papel e montados de acordo com valores pessoais, fantasias, metas e percepções de expectativas sociais.

Até aqui, foram abordadas as formas elementares de autoextensão a que uma pessoa é suscetível. Há casos especiais que podem ser mencionados para que esta pesquisa se mostre mais profunda do que poderia ser caso fosse direto à questão central relativa aos veículos como Eu estendido dos consumidores de baixa renda. Os casos especiais a serem abordados são: coleções, dinheiro, animais de estimação, outras pessoas, e partes do corpo, conforme indicado na Tabela 3. 
Tabela 3: Casos especiais de autoextensão.

\begin{tabular}{|c|c|}
\hline Coleções & $\begin{array}{l}\text { São uma forma de autoextensão que pode ser a tradução de boas lembranças (PONCHIO; STREHLAU, 2011). Para Belk (1988), } \\
\text { elas podem ser percebidas como intermináveis uma vez que, quanto mais completas, mais valiosas para seus proprietários serão. }\end{array}$ \\
\hline Dinheiro & $\begin{array}{l}\text { Pode-se dizer que há sentimentos de poder aumentado, autoestima melhorada, maior possibilidade de se alcançar o amor sonhado, } \\
\text { sucesso na vida. A autoextensão pelo dinheiro pode fazer alguém se sentir melhor sob vários aspectos. Mas, para a maioria das } \\
\text { pessoas, o dinheiro pode continuar a ser apenas mais uma forma de tangibilizar desejos ocultos que estenderiam o próprio Eu. }\end{array}$ \\
\hline $\begin{array}{l}\text { Animais de } \\
\text { estimação }\end{array}$ & $\begin{array}{l}\text { Pode-se dizer que despertam sentimentos naqueles que veem o dono com seu "pet”. Sentimentos contrários também podem ser } \\
\text { despertados, já que o dono pode ter o "pet” como forma de se impor a “alguém” que a ele deva obediência. Costuma-se atribuir } \\
\text { caracteres do dono ao "pet” - uma tentativa de identificar a autoextensão do dono. Há indícios ainda mais patentes da autoextensão } \\
\text { do proprietário do "pet" sobre o mesmo, tais como: o nome dado e o tratamento dispensado similares ao que ocorre com uma } \\
\text { pessoa, a consideração que se possa ter com o "pet” elevando-o ao "status" de membro da família. }\end{array}$ \\
\hline Outras pessoas & $\begin{array}{l}\text { O sentimento de posse dos pais pelos seus filhos, de um cônjuge pelo outro, do patrão pelo empregado são casos deste tipo de } \\
\text { autoextensão. A autoextensão pode ser percebida, também, no momento da perda de um filho, esposa. Pode-se acrescentar a } \\
\text { ocorrência de acidentes com pessoas do próprio convívio. Pode-se citar os casos de estupro, conforme Belk (1988), em que o } \\
\text { estuprador é motivado por uma vontade de "ter” a vítima enquanto esta não o deseja e tem seu Eu violado pelo estuprador. Nesses } \\
\text { casos, não só o Eu da vítima é violado, como também o Eu de seus amigos e parentes. Em resumo, a autoextensão sobre outras } \\
\text { pessoas pode ser entendida como mencionado por Belk (1988, p. 156): “a incorporação de outros ao "eu” estendido pode envolver } \\
\text { uma 'objetificação' degradante dessas outras pessoas”. }\end{array}$ \\
\hline $\begin{array}{l}\text { Partes do } \\
\text { corpo }\end{array}$ & $\begin{array}{l}\text { Percebe-se que um cuidado maior com alguma parte específica pode representar o grau de valorização destinado àquela parte do } \\
\text { corpo. A perda de parte do corpo pode desencadear um sentimento de pequenez, capaz de alterar a identidade do Eu próprio. }\end{array}$ \\
\hline
\end{tabular}


Belk (1988), além dos casos especiais antes citados, também elencou algumas implicações do Eu estendido para a pesquisa do comportamento do consumidor, conforme o que segue: consumo indireto, o ato de presentear, doação de órgãos, disposição e descarte de produtos, o papel do eu estendido para a formação de sentido na vida e, por último, os cuidados com bens duráveis.

Como forma de exemplificar o consumo indireto mencionado por Belk (1988), pode-se citar o consumo por parte dos familiares, que embora não seja para si estendem o Eu de si próprio, pois seus filhos e cônjuge representam parte do seu eu estendido.

No que concerne ao ato de presentear, pode-se dizer que tal ato pode ser percebido como altruísta ou como mero gesto de obediência às regras de reciprocidade da sociedade. No entanto, Belk (1988) expõe que o ato de presentear pode agregar mais pessoas ao Eu estendido de quem presenteia. De outra forma, o autor também expõe o fato de que presentear alguém já pertencente ao próprio Eu estendido é mais autogratificante. Em contrapartida, o ato de presentear alguém no âmbito do próprio Eu estendido pode gerar alguma rivalidade entre cônjuges ou parceiros.

Em relação à doação de órgãos, Belk (1988) apresenta em seu trabalho que, pelo fato de se estar perdendo uma parte do corpo - ou por mau funcionamento ou por outro motivo -, o receptor de um órgão pode apresentar baixa autoestima, insegurança, ansiedade, sentimento de inferioridade. Além disso, são esperados em alguns casos uma forma de contaminação pelo Eu do doador. Assim, há casos em que o recebimento do órgão de um homem por uma mulher desperta o medo de se alterar sua preferência sexual. De forma similar, há casos em que um negro tem medo de sofrer alterações no seu corpo ao receber um órgão de um branco. Como se esses casos não fossem o bastante, também há casos em que o receptor espera "herdar" alguma capacidade ou habilidade do doador. Com relação ao doador, pode-se perceber que há o medo da perda de parte do seu Eu. Tal como se acredita que órgãos transplantados ou doados podem mudar alguém, Belk (2003) indica a crença das pessoas de que o uso de um bem específico pode até ser capaz de tornar magicamente alguém mais bonito, alegre ou confiante. Entretanto, quanto menos apegados à beleza como seu principal atributo, mais propensos à doação de órgãos. Também, daqueles indivíduos mais apegados à comunidade onde vivem, espera-se a doação dos órgãos por, 
justamente, valorizarem em um grau bastante elevado tal comunidade. Por fim, Belk (1988) afirma que os indivíduos mais materialistas são os menos propensos a doar seus órgãos.

No que tange à disposição e descarte de bens, McCracken (2003) afirma dois propósitos a serem atingidos com rituais de despojamento. Um seria apagar os significados associados ao dono anterior - o que pode ser percebido quando da compra de um carro usado em que se procede, o quanto antes, a uma revisão minuciosa. Outro seria a disposição propriamente dita. Belk (1988) relata casos de acumulação sem propósito, com a justificativa de que se for preciso em algum dia, se terá. Também apresenta evidências de retenção de bens pelo medo de que, sem eles, seja perdida parte da identidade do dono - o bem é visto como um elo entre passado, presente e futuro no processo de construção da história daquela pessoa. Momentos em que são percebidos progressos profissionais, pessoais - no campo intelectual ou afetivo - são vistos como momentos em que há crescimento e fortalecimento do Eu não estendido ou núcleo do indivíduo, momentos esses em que se espera maior desprendimento material. Da mesma forma, quando se tem a mudança da imagem do indivíduo ou do valor que este dá aos seus bens espera-se que os mesmos sejam postos em desuso ou dispostos a outrem. Por fim, Belk (1988, p. 159) afirma: "podemos especular que quanto mais forte o Eu não estendido ou núcleo do indivíduo, menor será a necessidade de adquirir, guardar e cuidar de um número de bens que formam uma parte do Eu estendido”.

Em relação ao papel do Eu estendido para a formação de sentido na vida, Belk (1988) apresenta pontos positivos e negativos da autoextensão sobre as posses. Como ponto positivo, aborda o fato de que o indivíduo constrói sua história e suas referências sobre os bens que possui ao longo da vida. Para Douglas e Isherwood (2009, p. 112-113), “o objetivo mais geral do consumidor só pode ser construir um universo inteligível com os bens que escolhe”. Porém, tal construção só será possível mediante intervalos temporais. Isto pois segundo os mesmos autores, "os bens de consumo são usados para marcar esses intervalos" (2009, p. 113). Como ponto negativo, Belk (1988) sugere que apoiar-se em bens pode ser uma armadilha para si, pois sem eles pode-se exacerbar um sentimento de pequenez ou coisa parecida. Em resumo, as posses não são só extensão do Eu de uma pessoa, elas agem como um depósito de memórias e significados (Belk, 2003). 
Quanto aos cuidados com as posses, McCracken (2003, p. 115) afirma que “os consumidores despendem um bom tempo limpando, discutindo sobre, comparando, refletindo sobre, mostrando ou mesmo fotografando muitas das suas posses”. Belk (1988) afirma que há uma relação entre o Eu estendido e as posses, bem como os cuidados a elas dedicados. Em outras palavras, quanto maior a importância de um objeto para seu dono, maior o cuidado que este terá com tal objeto. Para o presente estudo, é interessante citar que Belk (1988) menciona que os cuidados com carros por parte de seus proprietários são maiores quando os referidos carros são mais novos, recém-adquiridos ou estão em melhor condição que a “idade” poderia supor. Assim, para o autor, a relação proprietário-carro é "significativamente correlacionada com a centralidade do veículo para o eu estendido” (1988, p.158). Para McCracken (2003), um proprietário de automóvel que desperdiça tempo e energia extraordinários no cuidado de seu bem constitui uma busca por destacar e transferir algumas das propriedades ou atributos deste a si próprio. De outra forma, o que Belk (1988) expõe é que os proprietários de carros continuam a dar-lhes condição central no seu Eu, independente de o carro ser novo, seminovo ou antigo, pois para estes donos o fato de o carro ser ou não novo ou recém-adquirido ou não, não supõe ser menos deles e sim parte deles: o eu estendido.

\section{2}

\section{Simbologia do consumo para os consumidores de baixa renda}

Consumidores de baixa renda buscam otimizar seus gastos tentando adquirir os melhores produtos possíveis dentro de seu orçamento limitado, evidenciando a importância que o preço dos produtos tem para esta classe. Em contrapartida, em alguns momentos, pode-se perceber uma maior relevância dada à marca do produto, no intuito de se diferenciar dos seus pares (CHAUVEL; MATTOS, 2008).

No Brasil, para Barros e Rocha (2009), durante anos, consumidores de baixa renda não eram levados em consideração, pois empresas privilegiavam as classes A e B. “Tratava-se de uma verdadeira lógica da 'falta', seja de bens, de trabalho ou de 'consciência de classe”” (BARROS; ROCHA, 2009, p. 33). Porém, este cenário mudou com o advento do Plano Real, em meados da década de 1990, 
que representou um marco para o consumo das classes de baixa renda. Houve uma “explosão” de consumo de eletroeletrônicos bem como alguns outros produtos antes tidos como das classes superiores - produtos reconhecidamente de melhor qualidade e, consequentemente, preços mais elevados.

Barros e Rocha (2009) constataram que poder adquirir vários itens em uma mesma época é um desejo dos indivíduos de baixa renda. Na verdade, o sentimento de pertencimento implícito no relato das entrevistadas suplanta qualquer que seja o ágio que se venha a pagar em parcelamentos de longo prazo. O que importa mesmo é ter o bem não importando o custo final. Assim, para os autores, "ter acesso a determinados bens possibilitaria uma entrada na sociedade de consumo abrangente, e artigos como televisão, celulares parecem cumprir de imediato este papel” (2009, p. 38).

Conforme Barros e Rocha (2009), os consumidores de baixa renda dão muita importância ao atendimento simples, direto e cortês, de acordo com o recebido na Casas Bahia, por exemplo. Outro ponto bem recebido por este público é a confiança nele depositada mesmo quando este não dispõe de comprovação de renda suficiente. Além disso, ter em suas residências produtos que antes somente as patroas tinham é algo destacado no estudo. Assim, indivíduos de baixa renda mostram-se mais fiéis às marcas que os consumidores das classes A e B. Outra constatação é a de que alguns indivíduos veem como sinônimo de inferioridade, perante seus pares, o consumo de produtos reconhecidamente inferiores, pelo mercado. Isto ocorre pois, para Barros e Rocha (2009, p. 48):

Consumir é uma possibilidade para a saída da condição de "pobre" - ser “consumidor” de marca, então, surge como uma alternativa bastante desejada, por permitir uma forte visibilidade dentro do meio social em questão.

No entendimento de Castilhos e Rossi (2009, p. 51), “o consumo é um processo essencialmente cultural” e, portanto, através dele pode-se incluir ou excluir consumidores em algum contexto cultural. Ou ainda, conforme expuseram Douglas e Isherwood (2009, p.36), bens "podem ser usados como cercas ou como pontes”. Para Castilhos e Rossi (2009, p. 51):

O acesso a bens de consumo aumentou não somente para os ricos e patrões, mas também para os pobres e trabalhadores, que passam a ter a possibilidade de adquirir produtos que antes poderiam somente ser consumidos pelas classes mais altas. 
Castilhos e Rossi (2009) identificaram como sendo, o consumidor pobre brasileiro, aquele que prioriza gastos com alimentação. É, também, aquele cuja estrutura familiar mostra ascendência dos homens (como provedores) sobre as mulheres (como gestoras do orçamento e que decidem o que comprar) e sobre os filhos. De acordo com os autores, o consumidor de baixa renda procura através do consumo conspícuo diferenciar-se dos seus pares. Essa seria uma forma de estabelecer, segundo Mattoso e Rocha (2008, p. 11), “finas distinções entre os que são mais e menos pobres”.

Castilhos e Rossi (2009) constataram que para estes consumidores a casa é o bem mais valioso, pois representa um refúgio, um porto seguro e, também, uma forma de diferenciação distanciando-os dos miseráveis - ou “pobres-mesmo”. Através da casa pode-se conhecer os hábitos de consumo da família e, assim, é possível mostrar aos vizinhos sua “constelação de objetos” (CASTILHOS; ROSSI; 2009, p. 62) constituindo mais uma forma implícita de diferenciação.

Conforme Castilhos e Rossi (2009), os consumidores do morro dão contornos próprios aos produtos de massa. Semelhante à personalização de veículos pesquisada por Ramalho e Ayrosa (2009), os autores notaram que produtos de massa tendem a sofrer alterações - personalizações - no intuito de se tornarem diferentes dos demais. Por fim, os autores identificaram, por conta possivelmente - dessa busca por diferenciação a subdivisão da classe pobre, porém este aspecto não será aqui tratado.

O consumidor de baixa renda, em sua maioria, conforme identificado por Castilhos e Rossi (2009, p. 67), “possui baixa escolaridade e, invariavelmente, trabalha em empregos de baixa ou nenhuma qualificação”. Além disso, é, “pela posse de bens que os pobres se distinguem uns dos outros" (CASTILHOS; ROSSI, 2009, p. 69). De outra forma, os autores afirmam que determinados bens são comunicadores de uma condição de vida melhor. Dentre tais bens, o automóvel tem destaque por demandar grande quantia na aquisição e na manutenção. Assim, estes consumidores se colocam em um patamar acima dos demais pares e, por estes, passam a ser notados como diferenciados. Similarmente, Castilhos e Rossi (2009, p. 72) afirmam: 
O consumo é cada vez mais presente como elemento central na construção e manutenção de identidades na vida dos pobres urbanos. Seu caráter é, contudo, multifacetado e polissêmico - o mesmo bem pode ser usado como recurso para múltiplas reivindicações identitárias em nível individual, familiar e social.

Para D’Andrea et al. (2003), os consumidores de baixa renda são sensíveis aos preços, porém com o despertar de alguma desconfiança. Ademais, pelo próprio poder aquisitivo limitado, buscam minimizar quaisquer custos que se possa ter além do produto em si. Outros fatores que influenciam na decisão sobre onde comprar são o medo de ser maltratado, a menor variedade à sua disposição tornando a compra um ato menos tentador - e a facilidade de (re) negociação com o lojista local ou mesmo proceder a uma troca.

Mattoso e Rocha (2008) identificaram que não é raro o carro dos consumidores mais pobres ser instrumento de trabalho. Para Manning (2000), consumir é uma forma de definir a própria identidade. No seu estudo o cartão de crédito é identificado como o financiador da extensão do consumidor. Isto ocorre, pois, produtos (bens ou serviços) tangibilizam as diferenças sociais (MATTOSO; ROCHA, 2009). Complementando a ideia de Manning (2000), Barbosa (2004, p. 24) afirma:

Embora possamos dizer que através do consumo “construímos” identidades, um número maior de vezes a confirmamos e reconhecemo-nos em produtos, objetos e itens da cultura material que são "a nossa cara” ou que reafirmam e satisfazem aquilo que julgo ser meus gostos e preferências.

Para Prahalad (2010), o consumidor sente que existe quando está atrelado a uma empresa através de um contrato ou mesmo de um simples cartão de crédito. Tal sentimento é reflexo de sua, agora, identidade legal. Assim, percebe-se uma forma orgulhosa de agir ou mesmo falar, ou ainda, exibir o que, para muitos, seria uma espécie de símbolo da própria existência. Em resumo, na abordagem acerca da identidade do consumidor, Prahalad expõe que o consumidor dá às posses o significado de sua própria existência no mercado.

Segundo Ponchio e Aranha (2009), os consumidores de baixa renda veem com bons olhos o endividamento através de crediário para aquisição de bens, ao contrário do que ocorre quando o endividamento é para ter dinheiro em mãos. Aqui representa dizer que os indivíduos de baixa renda podem ser motivados por uma carência própria (BELK, 1988), levando-os a uma postura materialista, justificando para eles mesmos o autoendividamento para aquisição de bens. Os 
autores concluíram que o materialismo é capaz de praticamente dobrar as chances de endividamento através de carnês de crediário por parte dos consumidores de baixa renda. Dito de outra forma, pela avidez em ter bens, os consumidores de baixa renda se lançam ao endividamento.

Já Suarez, Motta e Barros (2009) constataram através de seu estudo que os patrões são vistos pelo público de baixa renda como esbanjadores e possuidores de bens em fartura. Porém, também foi evidenciado que os consumidores de baixa renda vivem em um regime de escassez, restrições e sonhos de consumo. Aqui, nota-se uma autodiferenciação estabelecida pelos pobres conforme o evidenciado em Castilhos e Rossi (2009, p. 66) - “pobres e 'pobres-pobres'” - quando uma das personagens comenta: "Tú já imaginou a Nete no estrangeiro, dando uma de patrão e fazendo compras?” (SUAREZ; MOTTA; BARROS, 2009, p. 214). É interessante notar o tom desta fala em que está implícita certa impossibilidade “inerente” ao cidadão de baixa renda - de consumir determinados itens vistos, até então, como exclusivos das classes mais abastadas.

Assim, fica evidente o desejo dos consumidores de baixa renda de terem acesso aos "produtos dos ricos”. Quando isso ocorre, os autores tratam como transformação. Entretanto, os mesmos autores destacam que “o consumo, quando fora dos 'padrões' estabelecidos para a classe mais baixa, não é prêmio, mas um verdadeiro castigo” (2009, p. 220). O que se buscou ilustrar aqui foi o mau uso por vezes feito por usuários “despreparados” para o consumo de determinado produto - bem ou serviço.

De acordo com Casotti, Suarez e Deliza (2009), a despeito da recorrente escassez já antes relatada, o consumidor de baixa renda se satisfaz ao consumir seja o que for - conforme este estudo - sem, frequentemente, a possibilidade de escolha e muitas vezes sem prazer. Entretanto, conforme estudos anteriormente citados há um anseio por parte destes consumidores por consumir itens voltados aos ricos. Neste caso, a “comida de rico” (CASOTTI; SUAREZ; DELIZA, 2009, p. 239), pois esta é vista como mais sofisticada e saborosa. Fica implícito que esta é melhor que a do indivíduo de baixa renda.

Chauvel e Mattos (2008) notaram haver uma coexistência de duas racionalidades onde uma é simbólica / antropológica e está baseada na cultura, nos relacionamentos e hierarquia social presentes, e outra deriva da recorrente escassez de recursos destes consumidores. Também notaram um contraste entre os 
relatos dos consumidores de baixa renda pesquisados indo desde sentimentos de poder, prazer, realização, liberdade, autossatisfação até frustração, impotência por não terem recursos suficientes à aquisição de tudo o que eles desejavam. Transpareceu, assim, um forte anseio por ter o suficiente para esbanjar - como os ricos fazem, conforme o constatado no estudo de Suarez, Motta e Barros (2009), por exemplo. 


\section{3}

\section{Metodologia}

Neste capítulo, é apresentada a metodologia escolhida para a presente pesquisa. O mesmo se encontra subdividido em cinco seções, sendo elas: tipo de pesquisa, seleção dos entrevistados, o procedimento de coleta, procedimento de análise dos dados e as limitações do método.

\section{1}

\section{Tipo de pesquisa}

O presente trabalho de pesquisa busca o entendimento da relação do consumidor de baixa renda com seu carro de passeio, utilizando a teoria de "eu" estendido (BELK, 1988) como sua base. Mais precisamente, busca-se identificar e entender os significados por esses consumidores atribuídos ao carro de passeio de sua propriedade. Crotty (1998) supõe a construção dos significados pelos indivíduos baseada na experiência de vida desses. Creswell (2010, p. 31) corrobora essa ideia mencionando que:

Os indivíduos desenvolvem significados subjetivos de suas experiências, significados dirigidos para alguns objetos ou coisas. Tais s ignificados são variados e múltiplos, levando o pesquisador a buscar a complexidade dos pontos de vista em vez de estreitá-los em algumas categorias ou ideias.

A presente pesquisa busca compreender os significados associados por consumidores de baixa renda aos seus veículos e, portanto, entende-se que um estudo interpretativo seja o mais adequado para descrever o fenômeno em questão (CRESWELL, 2010). Ademais, a abordagem aqui será qualitativa, pois o objetivo é promover conhecimento inicial acerca do problema de pesquisa.

A escolha de tal metodologia se mostrou adequada, haja vista a sua adoção em outros estudos semelhantes, que tratam do self e do carro, feitos por Ponchio e Strehlau (2011) e Ramalho e Ayrosa (2009), por exemplo. Outros estudos também já se utilizaram desta visão interpretativista para estudar o comportamento de consumidores de baixa renda (BARROS, 2006; MATTOSO; ROCHA, 2005), Ainda segundo Zikmund (2006), esta pesquisa "não pretende fornecer evidências 
conclusivas para que se determine um curso de ação... é conduzida com a expectativa de que será necessária uma pesquisa subsequente para fornecer evidências conclusivas” (2006, p. 51).

\section{2}

\section{Seleção dos entrevistados}

No que se refere ao universo de pesquisa, este se limita aos indivíduos de baixa renda moradores da cidade do Rio de Janeiro. O critério utilizado para definir a classe social dos entrevistados está de acordo com o estabelecido pelo IBGE, onde a sociedade foi dividida em cinco classes sociais - conforme o anexo II. Consumidores de baixa renda seriam aqueles pertencentes às classes $\mathrm{C}, \mathrm{D}$ e E, seguindo o mesmo raciocínio que outros autores (PRAHALAD, 2006; NERI, 2010). Também era pré-requisito para participar da pesquisa que os entrevistados possuíssem carro de passeio próprio.

A fim de alcançar esse público, fez-se um esforço de divulgação entre amigos e vizinhos no sentido de intermediarem o contato a ele. Tais amigos e vizinhos forneceram - com a devida permissão - os telefones de pessoas do seu conhecimento para que o pesquisador fizesse o primeiro contato se identificando e explicando a pesquisa. Após tal explicação, os indivíduos que aceitaram participar combinaram dia e horário para a realização da entrevista em local de preferência dos indivíduos. Também foram abordados entrevistados, pontualmente na rua, por conta de seus carros chamarem atenção ora pelo zelo ora pelo estado geral de conservação do mesmo. Nessa abordagem preliminar o pesquisador se apresentou, explicou o trabalho em questão, forneceu seu contato e, subsequentemente, foi combinada a entrevista conforme mencionado anteriormente - local, dia e horário de preferência dos indivíduos ora abordados.

Ao todo, foram realizadas entrevistas com 20 consumidores com essas características. No intuito de se conseguir maior diversidade de informações pelas diferentes vivências, optou-se por entrevistar homens e mulheres, de diferentes bairros, com idades variando entre 32 e 71 anos com ocupações, formações e composições familiares diversas, conforme ilustrado na tabela 4. 
Tabela 4: Dados pessoais dos entrevistados.

\begin{tabular}{|c|c|c|c|c|c|c|}
\hline Entrevistado & Gênero & Idade & Profissão & $\begin{array}{c}\text { Estado } \\
\text { Civil }\end{array}$ & Bairro & $\begin{array}{c}\text { Faixa de } \\
\text { renda }\end{array}$ \\
\hline 01 & Masculino & 37 & Comerciante & Casado & $\begin{array}{c}\text { Vila } \\
\text { Isabel }\end{array}$ & 3 \\
\hline 02 & Masculino & 61 & Estofador & Casado & Andaraí & 2 \\
\hline 03 & Masculino & 32 & $\begin{array}{c}\text { Téc. em Manutenção } \\
\text { Elétrica }\end{array}$ & Casado & Andaraí & 3 \\
\hline 04 & Masculino & 61 & Agente de Segurança & Separado & Bangu & 2 \\
\hline 05 & Masculino & 42 & Rodoviário & Casado & Cosmos & 2 \\
\hline 06 & Feminino & 59 & Taróloga & $\begin{array}{l}\text { União } \\
\text { Estável }\end{array}$ & Tijuca & 2 \\
\hline 07 & Masculino & 71 & Perito Judicial & Casado & Tijuca & 3 \\
\hline 08 & Masculino & 40 & $\begin{array}{c}\text { Téc. Em } \\
\text { Copiadoras/Impressoras }\end{array}$ & Solteiro & Tijuca & 2 \\
\hline 09 & Masculino & 61 & Téc. Administrativo & Casado & Tijuca & 3 \\
\hline 10 & Masculino & 50 & Fotógrafo & Casado & $\begin{array}{l}\text { Campo } \\
\text { Grande }\end{array}$ & 3 \\
\hline 11 & Feminino & 53 & Assistente Social & Solteira & Tijuca & 3 \\
\hline 12 & Masculino & 66 & Aposentado & Casado & Tijuca & 3 \\
\hline 13 & Feminino & 34 & Assistente Social & Solteira & $\begin{array}{c}\text { Barra da } \\
\text { Tijuca }\end{array}$ & 3 \\
\hline 14 & Masculino & 44 & $\begin{array}{c}\text { Professor de Educação } \\
\text { Física }\end{array}$ & Casado & Tijuca & 2 \\
\hline 15 & Feminino & 39 & Cabelereira & Solteira & Catumbi & 3 \\
\hline 16 & Masculino & 44 & Servidor Público & Casado & Tijuca & 3 \\
\hline 17 & Feminino & 35 & Coord. De Operações & Solteira & Anchieta & 3 \\
\hline 18 & Masculino & 38 & $\begin{array}{l}\text { Gerente de Posto de } \\
\text { Combustíveis }\end{array}$ & $\begin{array}{c}\text { União } \\
\text { Estável }\end{array}$ & Tijuca & 2 \\
\hline 19 & Masculino & 51 & Servidor Público & Casado & $\begin{array}{c}\text { Éden - } \\
\text { São João } \\
\text { de } \\
\text { Meriti }\end{array}$ & 3 \\
\hline 20 & Masculino & 42 & Aux. de Manutenção & $\begin{array}{l}\text { União } \\
\text { Estável }\end{array}$ & $\begin{array}{c}\text { Del } \\
\text { Castilho }\end{array}$ & 2 \\
\hline
\end{tabular}




\section{3}

\section{Procedimentos de Coleta de Dados}

A técnica de coleta de dados a ser usada no presente estudo foi a de entrevista em profundidade. Segundo Zikmund (2006, p. 126), “as entrevistas em profundidade são entrevistas extensas não estruturadas que encorajam um respondente a falar de forma franca e livre, e em profundidade, sobre um tópico não disfarçado”. De forma semelhante, Boterf (1984, p. 57) afirma:

(...) é importante compreender (...) qual o ponto de vista dos indivíduos ou grupos sociais estudados acerca das situações que vivem. Qual a percepção destes sobre tais situações? Como eles a interpretam? Qual seu sistema de valores? Quais seus problemas? Quais suas preocupações? É preciso aprender qual é a lógica dos pesquisados (...).

Foi utilizado como balizador para as entrevistas um roteiro de entrevistas com as principais perguntas a serem feitas aos entrevistados. Seguindo o que Martins e Lintz (2012) indicam, buscou-se obter informações o mais detalhadas possível quanto à relação dos entrevistados com seus carros. Com o intuito de manter o máximo de atenção voltada aos entrevistados, optou-se por gravar as entrevistas, com o devido consentimento dos mesmos.

Durante a apresentação que antecedeu as entrevistas, deu-se ênfase ao fato de que todas as informações apuradas na entrevista seriam, única e tão somente, utilizadas com fins acadêmicos para a presente pesquisa. Além disso, enfatizou-se que o conteúdo das entrevistas só seria acessado ou mesmo manuseado pelo autor desta pesquisa e por seu professor orientador. Por fim, deu-se maior ênfase ao anonimato do entrevistado destacando-se que esse não seria, de forma alguma, identificado. E, de modo a deixá-lo mais à vontade, foi explicado que para a presente pesquisa não havia respostas certas nem erradas, somente as percepções, vivências ou afins de cada um quanto ao seu carro.

Vale destacar que foram feitos dois pré-testes das entrevistas, por meio dos quais não se evidenciou necessidade de alteração no roteiro das entrevistas. Notou-se, porém, no decurso das entrevistas, certa redundância entre algumas perguntas, tendo-se optado pela manutenção das mesmas a título de confirmação de respostas anteriores. Tal fato mostrou-se interessante, pois, em algumas 
entrevistas, funcionou não só como um confirmador das respostas anteriores como também um indutor na consecução de novas informações.

Faz-se necessário saber que o roteiro de entrevistas ora utilizado fora inspirado naqueles usados nas pesquisas de Silva (2007) e Franca (2013), com as devidas adaptações e acréscimos decorrentes da abordagem teórica e também da diferença tanto do público-alvo quanto da temática aqui abordada. Além disso, quase todas as entrevistas foram feitas, segundo Creswell (2010, p. 208), em “ambiente natural”, ou seja, em ambiente no qual o entrevistado se sentisse mais à vontade ora na garagem de sua casa ou edifício, ora no local de trabalho, perto do seu carro.

Vale ressaltar que em momento algum das entrevistas foi mencionado que o público-alvo era o de consumidores de baixa renda. Da mesma forma, quando os entrevistados foram solicitados a indicar a sua renda, - com base na tabela que lhes fora apresentada (anexo II) - as faixas de renda estavam numeradas de 1 a 5 da menor faixa de renda para a maior faixa de renda. O objetivo com essa medida - não usar classificação de renda por classes - foi não criar barreira, tampouco gerar constrangimento, entre entrevistador e entrevistados.

Além disso, no decorrer das entrevistas, as respostas obtidas por vezes ensejaram novas perguntas que não estavam previamente relacionadas no roteiro de entrevistas. Tal fato foi mais fortemente evidenciado nas entrevistas 7, 10 e 11 . Isso, segundo Zikmund (2006, p. 126), é característico desta forma de coleta de informações, pois: "as entrevistas em profundidade são entrevistas extensas, não estruturadas que encorajam um respondente a falar de forma franca e livre, e em profundidade, sobre um tópico não disfarçado”.

É importante ressaltar que, ao final de todo o procedimento, contabilizouse, aproximadamente, 11 horas de entrevistas gravadas.

\section{4}

\section{Procedimento de análise de dados}

A forma de análise dos dados coletados se iniciou por meio da transcrição das entrevistas. Com tais transcrições em mãos, começou-se um processo de leitura das entrevistas, para o pesquisador tomar mais consciência de seu conteúdo. 
Aos poucos, foi possível começar a encontrar semelhanças e diferenças dos relatos dos entrevistados entre si e com o referencial teórico do estudo. A partir dessa análise inicial, as categorias do estudo surgiram. Sua descrição é feita no capítulo 4.

\section{5}

\section{Limitações do método}

A metodologia aqui utilizada não é infalível, portanto, apresenta suas limitações. Constituem limitações do método ora utilizado: quantidade limitada de entrevistas, diferentes backgrounds dos entrevistados e a limitação do próprio entrevistador.

Quanto à limitada quantidade de entrevistas, torna-se evidente que não há uma busca por generalizações no que concerne às vivências e percepções dos entrevistados. Como é característico de pesquisas qualitativas, a intenção aqui é, segundo Zikmund (2006), gerar insights.

Segundo Zikmund (2006), as limitações das entrevistas se dão, principalmente, porque pode haver uma dificuldade de entendimento da linguagem dos entrevistados ou mesmo destes pelo entrevistador, dada a possível diferença de classe social ou backgrounds entre eles. Influenciam o processo de entrevistas, segundo o autor, o tom de voz, a aparência e até mesmo o fato de terse de reformular uma ou outra pergunta para melhor entendimento do entrevistado. Da mesma forma, Creswell (2010) afirma ser o entrevistador um limitante do método, dado que as pessoas podem se sentir pouco à vontade em relatar suas particularidades. Esse autor ainda apresenta o fato de as informações serem obtidas de acordo com o background dos entrevistados como fator limitante do método por se constituir um viés. Além disso, conforme Bertucci (2011, p. 65), "o entrevistado pode omitir, falsear ou ter modos muito particulares de interpretar dados fenômenos, tanto consciente quanto inconscientemente”. 


\section{Análise e Interpretação dos Resultados}

O presente capítulo tem por objetivo analisar e interpretar o conteúdo coletado através das entrevistas. Durante a análise das mesmas, foram identificadas cinco categorias, a saber: Carro como referência ao passado, à família e como família; Carro como referência ao corpo; Referência à posse; Referência à condição financeira ou status; e Referência à disposição e descarte. Assim, baseado nos relatos dos entrevistados e em sua associação com o referencial teórico, buscou-se inferências acerca do melhor entendimento dos significados atribuídos ao carro e como os carros são representados como "eu" estendido dos consumidores de baixa renda.

\section{1}

\section{Carro como referência ao passado, à família e como família}

Este tópico abrange os relatos feitos pelos entrevistados de baixa renda que remeteram a suas experiências passadas como consumidores e que foram marcantes em suas vidas. São objeto deste tópico as referências que os influenciaram a tomar gosto por carros e à sua compra. Entre as referências, foram citados familiares e como seus sentimentos sobre carros transbordaram para os entrevistados, conforme declara o Entrevistado 1: "Meu pai sempre gostou de carros. Sempre teve carros. Sempre, quando a gente era criança, tinha aquela brincadeira de entrar no carro, dirigir, fingir que tá dirigindo”.

O gosto por carros relatado pelo Entrevistado 1 talvez esteja de acordo com "uma verdadeira lógica da 'falta” ou, ainda, "uma hierarquia de escolhas" (BARROS, 2006), dado o fato de associar o carro a "brincar sempre", possivelmente um dos poucos meios de lazer disponível ao entrevistado. Também, é patente o papel do carro na formação de sentido na vida do entrevistado em questão, por fazer parte da construção da própria história, ocupando - o carro - um lugar de destaque no seu dia a dia e sendo tomado como referência de algo bom no seu passado - no caso, sua infância - conforme preconiza Belk (1988). 
Nessa linha, o Entrevistado 14 indica que, além do pai, seus irmãos também foram grandes influências para ele próprio ter fortes sentimentos positivos quanto a carros, pois “dois deles sempre tiveram carro”. O mesmo entrevistado afirmou que a família, praticamente, crescera em torno de carros, sendo que suas memórias mais vívidas são associadas a um Volkswagen Fusca do pai. Ademais, mencionou que o domingo era dia de dar atenção ao carro, quando o pai fazia sua manutenção.

Desta forma, e por terem - na maioria dos casos - sofrido influência de seus familiares, depreende-se que, no grupo pesquisado, a influência para a compra de um carro pode residir no passado do núcleo familiar, não tendo havido qualquer relato acerca de influência alheia à família. Houve, sim, casos sem referência ao passado, em que a compra se deu por outros fatores que serão apresentados adiante.

É curioso indicar o fato de que todos os entrevistados que declararam referências ao passado foram do gênero masculino e influenciados por outros homens (pai, tio ou irmão). Infere-se, assim, que o carro aparece como um elo na corrente familiar, em sua porção masculina, tornando, talvez, os homens consumidores “naturais” de carros.

Essa influência familiar sobre a percepção dos entrevistados sobre seus carros parece mudar, também, a forma como percebem o veículo, quase como se fosse outro membro da família, como um "veículo de estimação", que merece atenção e carinho. Houve entrevistado que mencionou haver certo estranhamento quando o carro "não vai junto” a algum lugar. Conforme o Entrevistado 1 relata, seu filho sempre lhe pergunta, quando vão sair de casa: “vai de carro, não?!”. Da mesma forma, o Entrevistado 5 também reforça a ideia de que seu carro "faz parte da família”. Tais relatos confirmam a noção de que os consumidores são identificadores e formadores de identidades que se constituem das representações do "eu" baseadas nos significados a elas atribuídas (ARNOULD: THOMPSON; 2005). Assim, os consumidores podem considerar seus carros como parte de suas famílias (PONCHIO: STREHLAU; 2011).

Tal percepção de que o carro é um membro da família chega a extremos de emocionar os entrevistados quando falam, com lágrimas nos olhos, do vazio que sentem quando o carro não está por perto deles: “É meu filho! Quando eu o deixo na oficina, fico olhando para aquele vazio na garagem” (Entrevistado 18). O 
entrevistado, nesse relato, apresenta preocupações relacionadas à insegurança do que alguém poderia fazer a seu carro sem ele por perto, como se o automóvel fosse vulnerável sem seu proprietário, assim como um filho seria sem seus pais. Quando sabe que seu carro apresenta problemas e, por isso, precisa ser levado a uma oficina mecânica, age como se fosse um filho no hospital, dado que o entrevistado se apresenta desconfortável com a situação e, desde o começo do relato, pôs a mão no peito como se seu coração estivesse a sofrer.

De forma diferente, o Entrevistado 3 afirmou ser o carro um integrante da família “porque ele gasta igual ao meu filho”. Todavia, fez essa afirmação de maneira desdenhosa, pois consegue distinguir mais claramente que "carro é carro".

\section{2}

\section{Carro como referência ao corpo}

Neste tópico, busca-se mostrar até onde pode ir o gosto - ou o amor - dos consumidores de baixa renda pelos seus carros. Assim, são analisados relatos que comparam seus carros a seus corpos ou partes específicas dos mesmos. Aqui, pode-se perceber quanta falta faz o carro quando comparado ou mesmo percebido como parte de si. Nota-se a autoextensão pela incorporação do objeto à pessoa (BELK; 1988, PONCHIO; ARANHA; 2011). É interessante destacar que, dos 20 entrevistados, apenas dois não manifestaram um nível de importância que significasse, o carro, como parte dos seus corpos ou mesmo que os completasse fisicamente de alguma forma.

Do total de entrevistados, alguns afirmaram perceber “claramente" seus respectivos carros como partes de seus corpos, tais como ilustra o depoimento a seguir: "seria como um membro meu, algo como uma mão. Eu viveria sem uma mão, mas me faria muita falta” (Entrevistado 16). Ao dar seu depoimento, o entrevistado passava as mãos no rosto olhando para cima como se perguntasse a si como seria sua vida com uma mão a menos. Outro respondente mencionou que seu carro seria seus braços, “porque me permite fazer as coisas” (Entrevistada 17). Nesse momento, a entrevistada projetou seus braços ao entrevistador, como se estivesse mostrando algo - uma ferramenta, talvez - e com certo ar de incerteza, possivelmente por não saber se os braços seriam uma estimativa tão adequada 
comparativamente à importância do carro. Por sua vez, o Entrevistado 7 declarou: “o meu carro é como uma extensão minha. Minhas pernas. Não consigo sair sem ele”. Embora esses entrevistados tenham feito uma relação de seus carros com membros, possivelmente por associarem mãos, braços e pernas à locomoção, dois entrevistados viam seus carros como seus corações, como se fossem a força pulsante que lhes movimenta diariamente.

Depreende-se, assim, que a noção de Belk (1988) de que as pessoas se sentem mais capazes de fazerem o que querem e devem com independência é corroborada nesses relatos ao que o autor classificou como processo de autoextensão pelo controle ou pelo domínio, no qual as pessoas se sentem capacitadas pelas suas posses.

Ao fazerem referência a seus carros como partes de seus corpos, essa associação levou diversos entrevistados a declararem que, com seu carro atual, são despertados sentimentos de completude e incompletude. Demonstram isso, por exemplo, quando alegaram que "todo homem se sente mais completo" (Entrevistado 7) ou "estou incompleta com ele... não estou satisfeita" (Entrevistada 6). Esse sentimento de incompletude pode ocorrer porque os entrevistados não percebem um automóvel como responsável por lhes gerar ganhos de saúde ou de recursos financeiros, e por ser apenas um bem que possuem para lhes servir, conforme o que disse o Entrevistado 12: "todos os carros que tive, foram na intenção de me servir”. De outra forma, pode-se inferir que tais declarações em relação ao sentir-se mais completo ou não corroboram a noção de Belk (1988) do “eu” não estendido (núcleo do indivíduo) versus a necessidade de bens na composição do “eu” estendido. Isto pode ser visto, pois nota-se, nos relatos e nos comportamentos apresentados pelos entrevistados, um sentimento maior que, supõe-se, qualquer bem fosse ou deveria ser capaz de despertar nos seus proprietários. Decorre daí a suspeita de que sejam seus núcleos individuais mais fracos que a necessidade, declarada por Belk (1988), de adquirir, guardar, e cuidar de bens os quais formam parte do 'eu' estendido" dos indivíduos.

No que concerne aos cuidados com as posses, como se partes do corpo fossem, conforme preconiza McCracken (2003), os entrevistados consomem consideráveis tempo e energia na busca de transferirem, para si, algumas propriedades ou atributos dos seus carros. Dos entrevistados que declararam tomar 
cuidados com seus respectivos carros, alguns atrelaram a boa aparência e limpeza - principalmente esta última - à identidade e a formação das suas imagens perante terceiros. De forma análoga, Barros e Rocha (2007) também constataram em seu estudo com empregadas domésticas do Rio de janeiro que, para elas, ter a casa limpa e arrumada significa que elas também são limpas. Desta forma, no presente estudo, encontrou-se declarações alinhadas com McCracken (2003), tais como: “Se o carro está limpo, significa que sou uma pessoa limpa” (Entrevistado 4). Ou: “Carro sujo é sinal de relaxamento” (Entrevistado 10). Ou, de outra forma mais enfática e reveladora acerca do que vão pensar as pessoas a respeito dele: “Claro!! Não vou andar com um carro sujo por aí” (Entrevistado 20). De outro modo, tais declarações corroboram a preocupação da representação do “eu” frente à sociedade baseada nos significados atribuídos, no caso, à limpeza dos carros dos pesquisados, conforme preconizam Arnould e Thompson (2005) e Belk (2003).

\section{3 \\ Referência à posse}

Neste tópico, será abordada a posse do carro pelos entrevistados. É apresentada a visão dos consumidores de baixa renda ao elencar os benefícios proporcionados pelo carro em suas vidas, que servem de justificativa para a sua aquisição. Nesse sentido, foram mencionados os seguintes benefícios proporcionados por um carro: independência, conforto, autonomia, segurança e “os momentos que ele (carro) me proporciona” (Entrevistado 18).

Em alguns casos, a compra do carro se deu não somente porque proporcionaria ao entrevistado um ganho, mas, também, porque lhe possibilitaria fugir de situações de desconforto, tais como depender de transporte público coletivo ou de um carro emprestado (de parentes ou amigos ou vizinhos). Ao usar o carro alheio, pode-se pensar em algo semelhante à contaminação pela doação de bens, ou seja, se estaria a usar um carro de outra pessoa, escolhido de acordo com a cultura alheia aos quais se teria de se submeter (BELK, 1988). Ainda, havia entrevistados que tinham um carro mais antigo, de tal modo que não se sentiam mais seguros, nem confortáveis, com eles. Desta forma, corrobora-se a noção de Chauvel e Mattos (2008) de que consumidores do estrato social pesquisado valorizam uma boa relação custo-benefício em acordo, também, com Barros 
(2006) que argumenta que o comportamento dos indivíduos de baixa renda é pautado por uma "lógica da falta”.

No que concerne à utilidade, os respondentes declararam que o carro é usado para substituir o transporte público coletivo, nos deslocamentos casatrabalho e afins e, também, no lazer. E, portanto, usado como agregador da família e dos amigos. Nas palavras da entrevistada 17 "costumo levar muita gente". Assim, pode-se inferir o caráter de reforço dos relacionamentos sociais por parte do carro, de modo semelhante ao uso da internet por parte do público de baixa renda, os quais "utilizam a Internet como mais um meio para aplacar essa 'fome' de relacionamentos, ampliando suas redes de convivência” (BARROS; 2008). Desta forma, o carro, presente no cotidiano dos consumidores, passa a ter um valor considerável dada a sua significação (DOUGLAS: ISHERWOOD, 2009).

De acordo com os vários relatos coletados, pode-se chegar aos principais sentimentos e sensações declarados pelos entrevistados sobre seus carros: alívio, carinho, conquista, felicidade, independência, (in) satisfação, liberdade, paixão, poder, prazer, realização, segurança e vitória. Nesse sentido, um dos pesquisados declarou se sentir “o senhor dos anéis” (Entrevistado 7), em relação ao poder que sente ter com seu carro, enquanto outro declarou: "por mais que seja antigo, velho, você passa a criar um vínculo com o carro, a gostar dele” (Entrevistado 5).

Depreende-se daí um forte relacionamento proprietário-carro o qual faz parte da construção da história pessoal de cada um dando sentido à vida destes proprietários, conforme Belk (1988). De outra forma, percebe-se que ter um carro passa a ser o significado da própria existência (PRAHALAD; 2010) ou ainda que é preciso ter para ser (BELK; 1988).

A Entrevistada 6 afirmou ter recebido o carro como um presente do marido. Entretanto, a entrevistada em questão declarou: “Isso foi invenção do meu marido. Eu não gosto de Ford. Prá mim, o melhor seria Volkswagen. Detesto essa cor”. Tais afirmações guiam esta análise na direção do que Belk (1988) chamou de consumo indireto, no qual o "eu” de quem presenteia pode se estender mais que o "eu” de quem ganha o presente. Isto, pois o presenteado, no caso, já faz parte do "eu” estendido daquele que presenteou. Assim, pode-se pensar que o ato de presentear pode não aumentar o “eu” estendido de quem presenteou ou, no pior dos cenários, reduzi-lo dada a insatisfação declarada pela entrevistada 6. De outro modo, cor, estilo, condição ou estado de conservação e até a combinação de bens 
- neste último caso pode-se pensar em acessórios acrescentados ao carro - podem levar a inferências a respeito do proprietário (BELK; 2003).

Verificou-se junto aos respondentes que há proprietários que se mostram indiferentes quanto a qualquer ocorrência ou dano aos seus carros e há aqueles que se importam profundamente. Ademais, foi possível verificar como se sentiram os proprietários nesses momentos: “foi horrível” (Entrevistado 9), “culpado” (Entrevistado 20), “chateado” (Entrevistados 10 e 19), “foi uma das piores experiências da minha vida. Eu me senti muito invadida” (Entrevistada 11), “de mãos e pés atados, sem poder trabalhar" (Entrevistado 2), “me senti muito mal, insegura” (Entrevistada 13), "gerou uma certa raiva” (Entrevistado 8), "mal” (Entrevistado 17) e " me senti muito mal, como se tivesse perdido um parente" (Entrevistado 18). Infere-se de tais declarações que quanto mais o “eu” dos consumidores se estende nos seus respectivos carros, mais dependente deles (os carros) eles se tornam, em um processo de autoextensão pelo controle ou domínio (BELK, 1988). O carro funciona como um bem capacitante.

No que tange aos cuidados com seus carros, notou-se que alguns consumidores são pouco ou quase nada zelosos, enquanto outros pecam pelo excesso. De acordo com o apurado na pesquisa, poucos entrevistados declararam não se preocupar com os cuidados ao carro, dada a sua idade e condição de saúde. Quanto aos demais entrevistados - que se declararam preocupados com os cuidados ao carro em algum nível -, um grupo afirmou ter como preocupação de cuidado mínimo a manutenção mecânica básica, lavagem periódica e aspiração do interior.

Verificou-se, conforme o que preconiza Belk (1988), que o carro recémadquirido desperta maior interesse no dono em cuidá-lo, conforme segue:

Nesse eu estou tendo cuidado (risos). Minha irmã até falava que "esse carro você não vai deixar o lixo que era o seu, não". Ficava dois meses sem lavar o carro. Com criança, então... Lixo, tirava bolsa de lixo quando ia lavar o carro. Nesse carro, agora, de semana em semana, eu passo um pano, dou uma lavada, uma aspirada. (ENTREVISTADO 1)

De outro modo, verificou-se uma contradição na fala do entrevistado 3: “não sou muito cuidadoso, mas sou aquele cara que tira um dia prá limpar”. Em contrapartida, o entrevistado 2 afirmou: 
Antigamente passava um domingo fazendo. Ninguém faz uma limpeza melhor do que o próprio dono do carro. Futuca tudo, faz tudo. Os caras passam um pano e acham que está bom. Um planeta de sujeira (risos). Eu tiro tudo. Tiro banco, tiro tudo. O carro fica no osso. Depois eu monto. Eu passo um dia. Futuco tudo. Tiro rodas, limpo. Passo um dia. Quando é de noite, já estou cansado. (ENTREVISTADO 2)

Corrobora-se, assim, a noção de Belk (1988) de que os donos se dedicam mais a seus carros enquanto estes estão novos, são recém-adquiridos ou estão em bom estado de conservação dado o tempo de sua existência. Ademais, confirma-se a noção de McCracken (2003) de que os consumidores despendem muito tempo se dedicando às suas posses.

\section{4}

\section{Referência à condição financeira ou ao status}

Durante as entrevistas, nenhum dos entrevistados declarou que o carro lhe conferia status frente aos demais consumidores de baixa renda. Entretanto, acreditam que a posse do carro pode despertar, nos outros - amigos, familiares ou vizinhos -, um sentimento de que aqueles que possuem tais bens são indivíduos com maiores recursos, conforme ilustram os relatos a seguir: "pensam que estava melhorando (financeiramente), que estava com dinheiro, que estava rico. Te olham com outros olhos” (Entrevistado 2); “Acham que está sobrando dinheiro” (Entrevistado 1). “Os vizinhos, é a mesma história de sempre: 'como ele conseguiu?! Com que dinheiro?!’” (Entrevistado 3); “Os vizinhos geralmente acham que a gente está com disponibilidade de dinheiro a mais. Qualquer pessoa que compre um carro passa a ser olhado de forma diferente” (Entrevistado 8); "Nunca pensei no que meus vizinhos iriam pensar. O carro, de certa maneira, tem uma relação com a pessoa. Antes era o carro da empresa, e agora é o meu” (Entrevistada 11); “Quando cheguei aqui, na época, nem todo mundo tinha condições de comprar um carro” (Entrevistado 14); “Alguns brincaram, dizendo que eu estava ficando rico” (Entrevistado 16); “Que estou com dinheiro. Dá prá perceber um sentimento de inveja, de cobiça, mas também sentimentos bons de amigos” (Entrevistada 17); “O status que ele me proporciona. Onde moro, os carros são bem mais humildes” (Entrevistado 18); “Eles acham que melhorou um pouco (financeiramente). Eu percebia que eles me olhavam de uma forma 
diferente” (Entrevistado 19); “Acharam que eu não iria conseguir comprar o carro” Entrevistado 20). Pensam “que sou prestativo” (Entrevistado 20).

Tais relatos são corroborados por Castilhos e Rossi (2009) e Belk (1988) no que concerne à diferenciação dos pares pela posse de bens. Nesse sentido, Belk (1988) afirma que "somos o que temos".

Outro aspecto valorizado pelos consumidores de baixa renda pesquisados é a relação custo-benefício de seus carros. Nesse sentido, citaram como ponto forte a economia - ou o consumo mais eficiente de combustível - dos seus veículos, de um modo geral. Portanto, no que se refere a esta questão, corrobora-se a noção de D’Andrea et al. (2003), quando destacam o consumo racional - levando a relação custo-benefício em consideração - como item de peso na decisão dos consumidores de baixa renda. Algo similar também foi constatado por Barros e Rocha (2007) no consumo das empregadas domésticas que afirmaram usar o sabão de melhor qualidade só na segunda lavagem das roupas e, ainda, que o sabão de qualidade inferior era usado para lavar o chão numa clara otimização dos recursos.

Houve respondentes que alegaram ter feito o parcelamento do carro para continuarem consumindo outros bens no mercado, conforme Barros e Rocha (2009) também perceberam em seu estudo. Nesse sentido, Castilhos (2007) afirma que “o crédito é visto como uma maneira de antecipar o consumo”. Em outras palavras, o parcelamento da compra do carro foi feito no intuito de o consumidor continuar pertencendo a esta sociedade do consumo em vez de se descapitalizar por completo ou mesmo se comprometer com a compra do carro em um valor mais alto mensalmente.

Ainda, de acordo com Ponchio e Aranha (2007), os entrevistados afirmam sentir-se bem quando estão adquirindo algo para si. Porém, quando questionados acerca do não pagamento, mostram-se incomodados com os altos juros dos financiamentos de carros. Assim, percebe-se que, o que antes era um prazer, pode se tornar verdadeiramente um castigo, conforme Suarez, Motta e Barros (2009) apontam.

Além disso - e talvez mais contundente -, é o relato de que "talvez me vejam de forma diferente, porque hoje em dia, as pessoas valem pelo que têm” (Entrevistada 15), o que pode ser explicado por Belk (1988), Arnould e Thompson (2005), Castilhos e Rossi (2009) ou, ainda, Prahalad (2010). De acordo com Belk 
(1988), os consumidores podem entrar naquilo que ele chamou de rivalidade de bens, ou seja, busca-se maior destaque na sociedade através de aumento de poder, prestígio, status. De outro modo, conforme Arnould e Thompson (2005) discutem que, as representações do “eu” são baseadas nos significados atribuídos às posses e, se a sociedade vê com melhores olhos aqueles que possuem um carro - como disse a entrevistada -, melhor será a representação do seu “eu”. Confrontando a fala da entrevistada 15 - "talvez me vejam de forma diferente, porque hoje em dia, as pessoas valem pelo que têm” - com o estudo de Castilhos e Rossi (2009), podese depreender que, para ela, ter um carro é motivo de diferenciação dos seus pares. Em última análise, a fala da entrevistada remete ao ter para ser, ou ao ter o carro como significado da própria existência frente aos demais (PRAHALAD; 2010).

\section{5}

\section{Referência à disposição e descarte}

Com relação à disposição e descarte dos seus respectivos carros, foram coletados depoimentos de certa indiferença, “algo normal” (Entrevistada 15), dito com um sorriso largo. Por outro lado, coletou-se depoimentos nos quais o proprietário disse:

Eu sou muito apegado ao carro, às minhas coisas. Se eu vendesse, seria para alguém que more bem longe, para eu não ver mais o carro. Seria muito difícil para mim. (ENTREVISTADO 20)

Nota-se em tais discursos uma nítida diferença de força entre o “eu” não estendido dos vários entrevistados (BELK; 1988). De modo semelhante, também se nota uma clara referência quanto à formação de sentido na vida (BELK; 1988). Em especial, com relação ao Entrevistado 20, nota-se o efeito negativo constituindo - seu carro - uma armadilha dada a sua aparente tristeza só em pensar ter de vender o bem tão querido. Percebe-se uma clara dificuldade de se desfazer do carro com medo de se autofragilizar.

Quando questionados acerca da possível venda de seu carro, os entrevistados em sua maioria admitiram vendê-lo na hipótese de comprar outro. Ilustra bem o que mais foi ouvido como resposta à pergunta sobre a venda: “venderia para comprar um melhor, mais novo” (Entrevistado 4). 
Sendo assim, percebe-se, no carro - ou melhor, na troca dele -, certa referência à construção de sentido na vida (BELK; 1988), pois a troca considerada teria como significado a melhora de vida e a construção de sua história. Além disso, nota-se que a venda do carro se dá somente - em sua maioria - quando da mudança do valor atribuído ao bem pelo indivíduo ou mesmo quando da mudança da imagem do indivíduo (MCCRACKEN; 2003). Neste último caso, poder-se-ia pensar na possível troca de ambiente de emprego - o que implica no convívio com novas pessoas - ou mesmo na ascensão na carreira ainda que fosse na mesma empresa. 


\section{Conclusão}

Este estudo teve como objetivo final entender quais são os significados atribuídos por consumidores de baixa renda a seus carros e como tais veículos são representados como uma extensão do self desses indivíduos. Para isso, foram feitas 20 entrevistas em profundidade com consumidores de baixa renda, da cidade do Rio de Janeiro, possuidores de veículos. A partir da análise dos dados, é possível chegar a algumas conclusões.

Conforme se pôde observar nas entrevistas, a relação carro-consumidor de baixa renda é tangenciada por muitos fatores culturais. Assim, pelo seu caráter relacional, sentimental, valores e afins o consumidor se afeiçoa ao carro, estendendo seu “eu” sobre ele.

Pôde-se inferir que o carro aparece como um elo na corrente familiar, fortalecendo as relações masculinas dado que se percebeu a influência masculina no processo de decisão pela compra do carro ou mesmo por se tomar gosto pelo carro ainda na infância tornando, talvez, os homens consumidores "naturais" de carros. Tal influência familiar parece mudar, também, a forma como os entrevistados percebem o veículo, quase como se fosse outro membro da família ou como um "veículo de estimação”.

Inferiu-se que os entrevistados relacionam seus carros com membros, possivelmente por associarem mãos, braços e pernas à locomoção. Alguns entrevistados viam seus carros como seus corações, como se fossem a força pulsante que lhes movimenta diariamente denotando a importância de seus carros para si.

Pôde-se inferir o caráter relacional que tem o carro, pois em torno dele as relações se constroem e se fortalecem. Além disso, o carro também foi percebido pelos entrevistados como um bem capacitante, pois tê-lo abre novas possibilidades. Entretanto, não ter o carro pode representar problemas tornandose, o consumidor de baixa renda, dependente do mesmo porque seu "eu” encontrase muito estendido no carro. 
Na categoria de análise referente à condição financeira e ao status, pôde-se perceber que os entrevistados, por terem um carro, não se percebiam em melhores condições que seus pares, porém, percebiam que algo no tratamento a eles dispensado havia mudado por terem justamente o carro. Ainda nesta categoria ficou novamente evidente o caráter de priorização dos recursos quando os respondentes afirmaram que o atributo economia do carro - uso mais eficiente do combustível - era o mais valorizado.

A última categoria da análise mostrou o quão estendido pode ser o "eu" dos consumidores de baixa renda nos seus carros através dos discursos que mostravam apego exacerbado em alguns casos e desapego - quase total - em outros. Evidenciou-se com isso o quão fortalecido ou não pode estar o núcleo do indivíduo. Ademais, pôde-se perceber que os consumidores de baixa renda, em sua maioria, só cogitaram se desfazer do carro no caso de uma troca por outro melhor e mais novo. Assim, o "eu” não deixaria de se estender no carro, apenas seria deslocado para outro carro mantendo-se um ciclo - talvez - vicioso.

Diante do acima exposto a CCT se mostra importante por cruzar crenças, valores e afins com o objetivo de se entender como e por que os consumidores de baixa renda adquirem um carro. Desta forma a CCT ajuda no entendimento dos desejos e anseios e significados do carro a este público e auxilia as empresas em como abordar melhor este público.

\section{1}

\section{Sugestões para futuros estudos}

Ao longo deste estudo exploratório alguns temas emergiram podendo ser objeto de investigação em pesquisas futuras e são mencionados a seguir.

Como sugestão de estudos futuros surge a importância das cores no processo de decisão de compra de carros pelas mulheres de baixa renda dado que algumas entrevistadas se mostraram influenciadas pela cor.

Outra sugestão seria procurar-se entender a satisfação do consumidor de baixa renda quanto ao carro adquirido haja vista a necessidade de se satisfazer demandas deste consumidor no seu dia a dia conforme evidenciado nas entrevistas. 
Como foi também observado nas entrevistas, nem sempre um presente é bem recebido. Sendo assim, outra sugestão seria apurar como fica o "eu" estendido de quem dá um presente que não agradou.

Dado que se pôde observar ao longo do estudo uma preocupação, em certos casos exacerbada, com relação aos cuidados com o carro poder-se-ia buscar entender como e por que os jovens de baixa renda cuidam de seus veículos “caidinhos” (carros velhos no dito popular).

De acordo com os depoimentos dos entrevistados, há uma preocupação com relação aos gastos com o carro e sua priorização frente outros gastos familiares, então mais uma sugestão seria procurar investigar como é a relação entre a consciência financeira do consumidor de baixa renda versus o "eu" estendido no carro.

E, por fim, conforme declarado por alguns entrevistados, o carro pode mudar a forma como as pessoas são vistas e/ou tratadas por terceiros, de tal modo que seria interessante entender: se somos o que temos, ao perdermos o que temos deixaríamos de ser quem realmente somos?

\section{2}

\section{Limitações do estudo}

No presente estudo pôde-se observar que há, por parte das cores dos carros, um apelo emocional que influenciou algumas das mulheres de baixa renda pesquisadas. Caberia, portanto, aprofundar-se esta questão quando da abordagem destas consumidoras.

Também, se pôde observar em alguns casos um nível de insatisfação exacerbado. Neste caso, poder-se-ia ter explorado mais esta questão levantando mais informações a respeito dos fatores geradores de tal insatisfação.

Outro ponto interessante a ser abordado aqui é o fato de um presente ter sido motivo de insatisfação. Dever-se-ia ter aprofundado a questão abordando até que ponto tal insatisfação gerada pelo presente influencia ou não no "eu" estendido tanto de quem recebeu quanto de quem deu o presente.

Pelo fato de alguns entrevistados terem declarado que não cuidavam de seus carros - talvez por questão de saúde ou mesmo de idade - dever-se-ia investigar se os mais jovens tendem a cuidar mais de seus carros ainda que sejam 
“caidinhos” ou se o nível de cuidado está ligado apenas à recentidade do carro adquirido.

Dada a precedência das contas familiares sobre o carro e seus gastos poder-se-ia enveredar por uma investigação mais apurada acerca deste tema.

Por fim, de acordo com o declarado por vários entrevistados, seus amigos, vizinhos e/ou familiares os veem de forma diferente por terem um carro. Assim dever-se-ia aprofundar o tema do ter para ser ou do ser por ter.

\section{3}

\section{Implicações gerenciais}

De acordo com os achados, as empresas podem aproveitar o fato de que as mulheres não são consumidoras “naturais” de carros para estreitar a relação carromulher dado que a maior influência que se percebeu nas entrevistas foi a de homens para homens.

No que concerne às influências à compra de um carro, estas ocorreram predominantemente dentro do núcleo familiar. Portanto, talvez seja interessante que as empresas do setor procurem associar os carros à família, mais precisamente ao crescimento da família fortalecendo, assim, a cultura do carro e dando mais sentido à vida e consolidando a história de vida destes consumidores.

Com relação às cores dos carros dos entrevistados, pôde-se observar que para os homens as cores não representam o que representam às mulheres. Assim, as empresas além de procurarem a aproximação das mulheres ao mercado automotivo - como dito anteriormente - deveriam buscar o entendimento do público feminino em relação às cores no intuito de alinhar produção, ofertas e campanhas publicitárias às expectativas destas consumidoras.

Dado o apego de alguns proprietários de baixa renda aos seus veículos, conforme algumas declarações, a metáfora do carro como um filho hospitalizado talvez possa ser usada em campanhas publicitárias de oficinas ou mesmo seguradoras reforçando a ideia de cuidados com os carros de forma a se manterem “saudáveis".

Da mesma forma, o carro como parte do corpo pode motivar empresas seguradoras, oficinas ou ainda de produtos de cuidados automotivos a enfatizarem 
a necessidade de se cuidar do carro. Isto, pois, ele "é parte do corpo" daquele consumidor e como tal deve ser cuidado.

Foi possível perceber ao longo deste estudo o caráter relacional conferido ao carro. Portanto, às campanhas publicitárias poder-se-ia acrescentar tal caráter. Também, seria interessante promover encontros entre proprietários novos, antigos e aspirantes a proprietários no intuito de se fortalecer o relacionamento entre as pessoas por ocasião do carro e também da imagem da marca como uma marca de relacionamentos e não só de produtos.

Como este estudo trata do público de baixa renda, especificamente, e este prioritariamente busca a melhor relação custo-benefício com a possibilidade de pagar em "suaves” prestações, seria interessante buscar-se adequar as ofertas a este público bem como buscar um relacionamento mais estreito quando da sua inadimplência. Dar-se-ia, assim, um tratamento menos frio que o que se tem percebido.

Por fim, poder-se-ia pensar na renovação da frota através de incentivos ao público de baixa renda tais como melhor valorização na troca por um carro 0Km ou mesmo seminovo, buscar um relacionamento mais próximo com este consumidor através do barateamento das revisões em concessionárias autorizadas no intuito de se manter tal cliente sempre em contato com a marca - caráter relacional - e informado acerca das novidades. 


\section{Referências bibliográficas}

ARNOULD, E.J.; THOMPSON, C.J. Consumer culture theory (CCT): Twenty years of research. Journal of consumer research, v. 31, n. 4, p. 868-882, 2005.

ARNOULD, E.; THOMPSON, C. Consumer culture theory (and we really mean theoretics): dilemmas and opportunities posed by an academic branding strategy. Research in consumer behavior, v. 11, p. 3, 2007.

ATKIN, R. Multidimensional man. Penguin, 1981.

BARROS, D.C.; PEDRO, L.S. As mudanças estruturais do setor automotivo, os impactos da crise e as perspectivas para o Brasil. BNDES Setorial, n. 34, set. 2011, p. 173-202, 2011.

BELK, R.W. Possessions and the extended self. Journal of consumer research, v. 15, n. 2, p. 139-168, 1988.

BELK, R.W. Materialism: Trait aspects of living in the material world. Journal of Consumer research, v. 12, n. 3, p. 265-280, 1985.

BECK, C.G. et al. Meu Celular e Eu: mensurando a extensão do self. Encontro Nacional dos Programas de Pós-graduação em Administração - ENANPAD, 2009.

BELK, R.W. Shoes and self. NA-Advances in Consumer Research, v. 30, 2003.

BARROS, C.; ROCHA, E. In: ROCHA, A. da; SILVA, J.F. da. Consumo na Base da Pirâmide: Estudos Brasileiros, Introdução. Rio de Janeiro: Mauad X, 2009.

BARBOSA, L. Sociedade de consumo. Rio de Janeiro: Jorge Zahar, 2004.

BERTUCCI, J.L.O. Metodologia Básica para Elaboração de Trabalhos de Conclusão de Cursos (TCC): ênfase na elaboração de TCC de pós-graduação Lato Sensu. 1. ed. 3. reimp. São Paulo: Atlas, 2011.

BELK, R.W. Extended self and extending paradigmatic perspective. Journal of Consumer Research, v. 16, n. 1, p. 129-132, 1989.

BARROS, C. Consumo, hierarquia e mediação: um estudo antropológico no universo das empregadas domésticas. XXX Encontro Anual da ANPAD, 2006.

BARROS, C.; ROCHA, E. Lógica de consumo em um grupo das camadas populares: uma visão antropológica de significados culturais. Anais do XXXI Enanpad. Rio de Janeiro, Anpad, 2007.

BARROS, C. A “invisibilidade” do mercado de baixa renda nas pesquisas de marketing: as camadas populares consomem ou sobrevivem. II Encontro de Marketing da ANPAD, 2006. 
BARROS, C. Apropriações da Tecnologia Computador em Lan Houses Populares: Entre Sociabilidade e Navegações Coletivas. Anais do XXXII ENANPAD, 2008.

CASOTTI, L.M.; SUAREZ, M.C. Dez anos de Consumer Culture Theory: delimitações e aberturas. RAE-Revista de Administração de Empresas, v. 56, n. 3, p. 353-359, 2016.

CASTILHOS, R.B.; ROSSI, C.A.V. In: ROCHA, A. da; SILVA, J,F, da. Consumo na Base da Pirâmide: Estudos Brasileiros, Introdução. Rio de Janeiro: Mauad X, 2009.

CASOTTI, L.; SUAREZ, M.; DELIZA, R. In: ROCHA, A. da; SILVA, J.F. da. Consumo na Base da Pirâmide: Estudos Brasileiros, Introdução. Rio de Janeiro: Mauad X, 2009.

CHAUVEL, M.A.; MATTOS, M.P. de A.Z. de. Consumidores de baixa renda: uma revisão dos achados de estudos feitos no Brasil. Cad. EBAPE.BR. Rio de Janeiro, v. 6, n. 2, p. 01-17, Junho 2008 .

CRESWELL, J.W. Projeto de pesquisa métodos qualitativo, quantitativo e misto. Porto Alegre: Artmed, 2010.

CROTTY, M. The foundations of social research: Meaning and perspective in the research process. Sage, 1998.

CASTILHOS, R.B. Subindo o morro: consumo, posição social e distinção entre famílias de classes populares. 2007.

Departamento Nacional de Trânsito. Código Nacional de Trânsito e Legislação Complementar. Disponível em: < Erro! A referência de hiperlink não é válida. $>$. Acesso em 14 de maio. 2016.

DOUGLAS, M.; ISHERWOOD, B. O mundo dos Bens: Para uma antropologia do consumo. Rio de Janeiro: UFRJ, 2009.

D`ANDREA, G.; STENGEL, E.A.; GOEBEL-KRSTELJ, A. Gerando valor para o consumidor emergente. Harvard Business Review Brasil, v. 82, n. 11, p. 95101, 2003.

FELDMAN, S.D. Nested identities: Studies in symbolic interaction, Jai Press Greenwitch, 1979.

FRANCA, M.S. Comportamento do consumidor endividado: um estudo exploratório da experiência de famílias na compra do carro. Rio de Janeiro, 2013. Dissertação (Mestrado em Administração) - Instituto COPPEAD de Administração, Universidade Federal do Rio de Janeiro, Rio de Janeiro.

Instituto para Desenvolvimento do Varejo. Boas notícias nesta volta ao caminho da prosperidade. São Paulo, 2009 Disponível em: $<$ http://www.idv.org.br/conjuntura-ccv-texto.aspx?IdTextoCCV=438 $>$ Acesso em: 25 de maio. 2016.

LAGUNA, E. Baixa renda sai do mercado de carros novos no Brasil. Valor 
Econômico, São Paulo, 09 mai. 2016. Disponível em: <http://www.valor.com.br// empresas/ 4553995/baixa-renda-sai-do-mercado-de-carros-novos-no-brasil > Acesso em: 23 de setembro de 2016.

LE BOTERF, G. Pesquisa participante: propostas e reflexões metodológicas. 1984.

MCCRACKEN, G. Cultura e consumo: novas abordagens ao caráter simbólico dos bens e das atividades de consumo. Rio de Janeiro: Mauad, 2003.

MATTOSO C. Q.; ROCHA, A. da. In: ROCHA, A. da; SILVA, J.F. da. Consumo na Base da Pirâmide: Estudos Brasileiros, Introdução. Rio de Janeiro: Mauad X, 2009.

MATTOSO, C.Q.; ROCHA, A. Significados associados às estratégias para solução de problemas financeiros dos consumidores pobres. Encontro Anual Nacional da Associação dos Programas de Pós-Graduação em Administração, 2005.

MANNING, R.D. Credit card nation. New York: Basic Books, 2000.

MARTINS, G.; LINTZ, A. Guia para elaboração de monografias e trabalhos de conclusão de curso. 2. ed. 5 reimp. São Paulo: Atlas, 2012.

MCCRACKEN, G. Culture and consumption: A theoretical account of the structure and movement of the cultural meaning of consumer goods. Journal of Consumer Research, v. 13, n. 1, p. 71-84, 1986.

NERI, M.C. A Nova Classe Média: O Lado Brilhante dos Pobres (The New Middle Class: The Bright Side of the Poor). Rio de Janeiro: FGV/CPS, 2010.

PONCHIO, M.C.; ARANHA, F.; TODD, S. Necessidades, vontades e desejos: a influência do materialismo sobre a dívida de consumo dos paulistanos de baixa renda. Anais do $31^{\circ}$ ENANPAD. Rio de Janeiro, 2007.

PONCHIO, M.C.; ARANHA, F. In: ROCHA, A. da; SILVA, Jorge Ferreira da. Consumo na Base da Pirâmide: Estudos Brasileiros, Introdução. Rio de Janeiro: Mauad X, 2009.

PRAHALAD, C.K. A riqueza na base da pirâmide: erradicando a pobreza com o lucro. Porto Alegre: Bookman, 2010.

PONCHIO, M.C.; STREHLAU, V.I. Eu Estendido no Interesse por Automóveis Clássicos: Estudo Comparativo entre Consumidores Paulistanos. FACEF Pesquisa-Desenvolvimento e Gestão, v. 14, n. 3, 2012.

RAMALHO, R.; AYROSA, E.A.T. Subcultura Tuning: a identidade estendida na personalização de automóveis. Revista de Ciências da Administração, v. 11, n. 24, p. 169, 2009.

RAPOPORT, A. Identity and environment: A cross-cultural perspective. Housing and identity: Cross-cultural perspectives, p. 6-35, 1981.

ROCHA, E. In: DOUGLAS, M.; ISHERWOOD, B. O mundo dos Bens: Para uma antropologia do consumo. Rio de Janeiro: UFRJ, 2009. 
SILVA, C. A classe $\mathbf{C}$ como consumidora saiu do mercado. O Estado de São Paulo, São Paulo, 22 jun. 2015. Disponível em: $<$ http://economia.estadao.com.br/noticias/geral,a-classe-c--como-consumidora-decarros--saiu-do-mercado,1732010>. Acesso em: 21 de maio de 2016;

SARAIVA, J. Mão na roda. Valor Econômico, São Paulo, 29 abr. 2016. Disponível em: <http://www.valor.com.br/empresas/4542947/mao-na-roda $>$ Acesso em: 22 de maio de 2016.

SCHOUTEN, J.W.; MCALEXANDER, J.H. Subcultures of consumption: An ethnography of the new bikers. Journal of consumer research, v. 22, n. 1, p. 4361, 1995.

SCHOUTEN, J.W. Selves in transition: Symbolic consumption in personal rites of passage and identity reconstruction. Journal of consumer research, v. 17, n. 4, p. 412-425, 1991.

SOUZA, I.L. et al. Uma Abordagem alternativa para a Pesquisa do Consumidor: adoção da Consumer Culture Theory (CCT) no Brasil/An Alternative Approach to Consumer Research: adoption of Consumer Culture Theory (CCT) in Brazil/Un Abordaje Alternativo para el Estudio del Consumidor: adopción de la Consumer Culture Theory (CCT) en Brasil. Revista Alcance (Online), v. 20, n. 3, p. 383, 2013.

SUAREZ, M.; MOTTA, P.C.; BARROS, C. In: ROCHA, A. da; SILVA, J. F. da. Consumo na Base da Pirâmide: Estudos Brasileiros, Introdução. Rio de Janeiro: Mauad X, 2009.

SILVA, R.R. da. Subcultura tuning: a identidade estendida na personalidade de automóveis. 2007. Tese de Doutorado.

TUAN, Yi-Fu. The significance of the artifact. Geographical review, p. 462-472, 1980.

VIEIRA, A. A gente se vê por aqui. O GLOBO, 20 de março de 2014, p. 24.

ZIKMUND, W.G. Princípios da pesquisa de marketing. São Paulo: Cengage Learning, 2006. 


\section{Anexos}

\section{Anexo I}

\section{ROTEIRO SEMI-ESTRUTURADO DE PERGUNTAS PARA ENTREVISTA}

Bom dia/ tarde / noite. Meu nome é Ricardo José Lodi Ferreira e sou estudante da PUC-Rio. Na entrevista que faremos hoje tenho como objetivo uma conversa sobre sua experiência de consumo de veículos de passeio.

De antemão gostaria de dizer que não há respostas certas nem erradas. Aqui o que interessa mesmo é saber realmente o que você pensa.

Gostaria de mencionar que você, em momento algum, será identificado e também seu nome não será citado na pesquisa. Assim, você pode ficar à vontade para contar o que quiser. Mais uma vez, gostaria de reforçar que tudo o que você me contar hoje só será usado com fins acadêmicos.

Para facilitar, eu vou gravar a entrevista para lhe dar mais atenção. Posso garantir que a gravação desta nossa conversa só será usada para a análise de tudo o que conversamos aqui, hoje e só. Tudo bem?

Fique à vontade para interromper a qualquer momento nossa conversa e tirar quaisquer dúvidas.

\section{Parte 1}

1) Você gosta de carros? Por quê? Fale um pouco mais desta história. [Alguém da família despertou seu interesse por carros?]

2) O que motivou você a comprar um carro?

3) Qual foi o seu primeiro carro? Fale um pouco sobre o seu primeiro carro. 
4) Você já teve quantos carros? [Caso o respondente tenha tido mais de um carro, perguntar: qual foi o carro de que você mais gostou? Por quê?].

5) Em relação ao carro de que você mais gostou o que você mais gostava nele?

6) Você faz ideia de quanto tempo precisou trabalhar para comprar esse carro?

7) Houve alguma influência para você comprar esse carro? [Influência de alguém, reputação (fama) da marca, etc.]

\section{Parte 2}

8) Qual carro você possui atualmente? [Identificação do modelo, marca, cor, preço, opcionais, etc.] Por que você comprou esse carro?

9) O que significou a compra do seu carro?

10) O que faz você sentir-se assim?

11) O que não podia faltar no seu carro? Por quê? Por que esta marca? Por que este modelo? Por que esta cor?

12) Que tipo de pessoa você acha que gosta deste modelo de carro?

13) Foi por isso que você comprou seu carro? Conte um pouco mais sobre isso.

14) Conta um pouco sobre como você é, sua personalidade?

15) Se você pudesse ter uma das qualidades do seu carro, qual seria? Por quê?

16) Você se sente mais completo com o seu carro? Como é isso?

17) Hoje você vê seu carro de forma diferente de quando ele não era seu? Por quê?

18) Qual a frequência e o tipo de uso do seu carro? Só você usa o carro?

19) $O$ que seus amigos acharam do seu carro?

20) $O$ que você acha que seus vizinhos pensam de você agora que você tem um carro para chamar de seu? Você acha que seus vizinhos viam você de forma diferente antes, sem carro? Por quê?

21) Como você se sente em relação aos seus amigos, vizinhos e/ou familiares, por ter comprado seu carro?

22) Onde você guarda / estaciona seu carro? Prefere estacionar em frente à sua residência ou em frente à de vizinhos? Por quê? Fale com mais um pouco de detalhes sobre isso. 
23) Você gosta de se expor com seu carro? [Sair com ele e deixar claro que ele é seu.] Por quê? O que isso significa para você?

24) Tem algo que se destaque no seu carro e que seja importante para você? O que é? Qual é o significado disso?

25) Para você, qual (ais) seria (m) a (s) principal (ais) diferença (s) entre você e as pessoas que não têm ou não gostam de carro?

26) O que você sente quando está dirigindo seu carro?

27) Que tipos de cuidados você tem com o seu carro e com que frequência você toma esses cuidados? Você gosta de zelar pelo seu carro ou não? Por quê?

28) Seu carro é como um integrante da família? Por quê?

29) Como foi comprado o seu carro: à vista ou parcelado? Se parcelado, o que mais influenciou na sua decisão: preço da parcela ou prazo de pagamento? Por quê?

30) Parcelar a compra do carro foi uma opção, uma necessidade ou um “capricho”? Por quê?

31) Ter o parcelamento do carro para pagar todos os meses é motivo de alegria ou de agonia? Por quê?

32) Você deixaria de comprar algo - para você ou sua família - para poder comprar o carro? Por quê?

33) Você deixaria de pagar alguma conta ou outro financiamento qualquer para pagar a parcela do seu carro? Por quê?

34) Você venderia seu carro? Caso você o vendesse, o que isso significaria para você?

35) Você já teve algum carro seu roubado? Como você se sentiu com isso?

36) Você já bateu o seu carro? Como foi o acidente? Quanto tempo demorou para você consertar o seu carro? Enquanto o carro não era consertado, como você se sentiu? 


\section{Parte 3}

37) De tudo o que falamos sobre a relação entre você e seu carro, há algo mais que não tenhamos falado e que você gostaria de registrar/acrescentar?

Qual é o seu nome?

Qual é o seu ano de nascimento?

Qual é o seu estado civil?

Qual é a sua profissão?

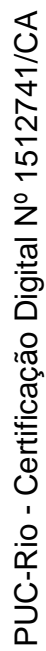

Em qual bairro você mora?

Qual é a sua faixa de renda familiar mensal? 


\section{Anexo II}

FAIXAS DE RENDA FAMILIAR MENSAL:

\begin{tabular}{ccc}
\hline $\begin{array}{c}\text { Faixa de } \\
\text { Renda }\end{array}$ & $\begin{array}{c}\text { Faixa de Renda em } \\
\text { Salários Mínimos (SM) }\end{array}$ & Faixa de Renda em R\$ \\
\hline $\mathbf{1}$ & Até $2 \mathrm{SM}$ & Até $\mathrm{R} \$ 1.760,00$ \\
$\mathbf{2}$ & De 2 até $4 \mathrm{SM}$ & $\mathrm{R} \$ 1.760,01$ até $\mathrm{R} \$ 3.720,00$ \\
$\mathbf{3}$ & De 4 até $10 \mathrm{SM}$ & $\mathrm{R} \$ 3.720,01$ até $\mathrm{R} \$ 8.800,00$ \\
$\mathbf{4}$ & De 10 até $20 \mathrm{SM}$ & $\mathrm{R} \$ 8.800,01$ até $\mathrm{R} \$ 17.600,00$ \\
$\mathbf{5}$ & Acima de $20 \mathrm{SM}$ & $\mathrm{R} \$ 17.600,01$ ou mais \\
\hline
\end{tabular}

Obs.: Tabela apresentada aos entrevistados quando da pergunta: "Qual é a sua faixa de renda familiar mensal?". 